\title{
RESIDUOS DE CLORPIRIFOS E FENITROTION EM CASCA E POLPA \\ DE PEPINO 'CAIPIRA' DETERMINADOS POR CROMATOGRAFIA EM FASE GASOSA
}

\author{
JOAOO CEZAR FERST \\ Engentheiro Agrónomo
}

Orientador: Prof. Dr. GILBERTO CASADEI DE BATISTA

Dissertação apresentada à Escola Superior de Agricultura "Luiz de Queiroz" da Universidade de São Paulo, para obtenção do titulo de Mestre em Ciências Biológicas. Área de Concentração: Entomologia.

$$
\begin{gathered}
\text { PIRACICABA } \\
\text { Estado de São Paulo - Brasil } \\
\text { Março - } 1991
\end{gathered}
$$


Ficha catalogräfica preparada pela Seção de Livros da Divisão de Biblioteca e Documentação - PCAP/USP

Ferst, João Cezar

F399r Resíduos de clorpirifos e fenitrotion em casca e polpa de pepino "Caipira" determinados por cromatografia em fase gasosa. Piracicaba, 1991.

$71 p$. ilus.

Diss. (Mestre) - ESALQ

Bibliografia.

1. Cromatografia gasosa 2. Pepino - Casca - Resíduo de pesticida 3. Pepino - Polpa - Residuo de pesticida 4. Pepino - Residuo de pesticida - Deter minação 5. Pesticida I. Escola Superior de AgricuI tura Luiz de Queiroz, Piracicaba.

CDD $\quad 635.63$ 
RESIDUOS DE CLORPIRIFOS E FENITROTION EM CASCA E POLPA DE PEPINO 'CAIPIRA' DETERMINADOS POR CROMATOGRAFIA EM FASE GASOSA

Joăo Cezar Ferst

Aprovada em: 16/04/1991

Comissăo Julgadora:

Prof. Dr. Gilberto Casadei de Batista ESALQ/USP Prof. Dr. Arquimedes Lavorenti ESALQ/USP

Prof. Dr. Keigo Minami ESALQ/USP

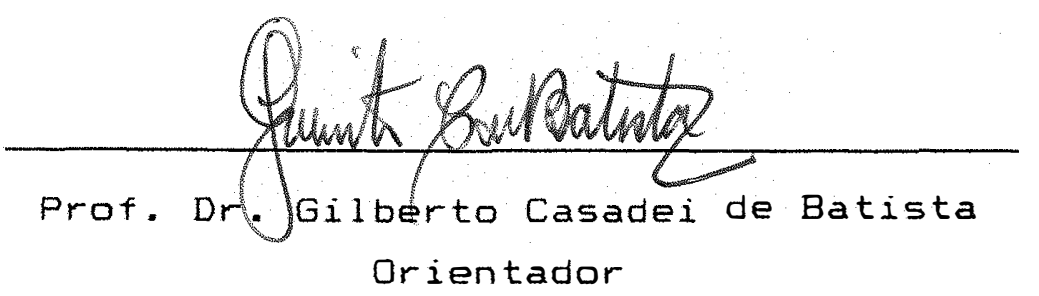


i i i .

A meus irmãos

Jose Carlos e Luiz Francisco

OFEREC.O.

À minha mãe Irede DEDICO. 
iv.

\section{AGRADECIMENTOS}

Ao Prof. Dr. Gilberto Casadei de Batista, pela orientação, dedicação, amizade e estimulo.

Ao Conseltho Nacional de Desenvolvimento Cientítico e Tecnológico - CNPq e a Fundaçăo de Amparo à Pesquisa do Estado de São Paulo - FAPESP pela concessão das bolsas de estudo no decorrer do curso de pós-graduaçăo.

Aos professores do Departamento de Entomologia pelos ensinamentos durante o curso.

Ao professor Keigo Minami do Departamento de Horticultura da ESALQ/USP pelas informaçz̃es sobre a condução da cultura.

Aos colegas do Curso de Pós-Graduação em Entomologia, pela amizade e incentivo no decorrer do curso.

Ás bibliotecárias Eliana e Kátia pela correção das referências bibliográficas e apoio durante o curso.

Ao amigo Vitoldo pela colaboração no experimento de campo.

Ao técnico de laboratório Edson Maciel pela colaboração nas análises laboratoriais. 
SUMARRIO

Página

LISTA DE FIGURAS ...................

vii

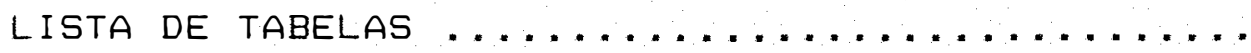

$\times$

RESUMO

$x i i$

SUMMARY

$x v$

1. INTRODUÇ ÃO

01

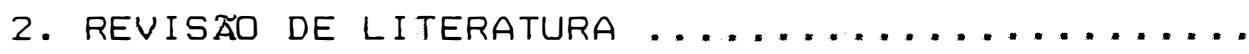

2.1. Aspectos básicos no estudo de residuos

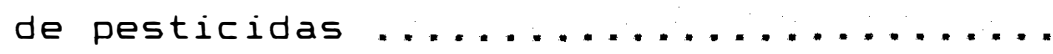

2.2. Residuos de inseticidas em hortaliças

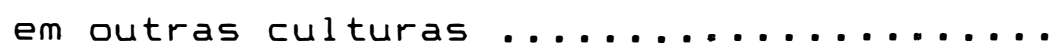

2.2.1. Residuos de clorpirifos em algumas

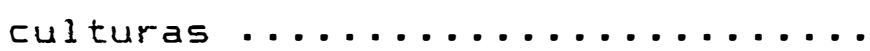

2.2.2. Residuos de fenitrotion em algumas culturas ...................

2.2.3. Amostragem para analise de resi-

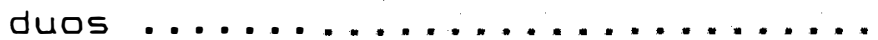

2.3. Caracteristicas da cultura e problemas

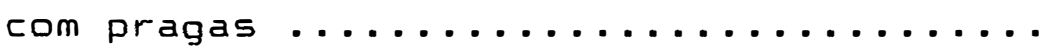

2.4. Clorpirifos ..................... 23

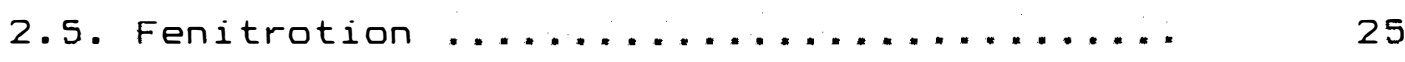

3. materiais e metodos ................... 27

3.1. Experimento de campo .............. 27

3.1.1. Semeadura e tratos culturais ..... 28

3.1.2. Pulverizaçăes dos inseticidas para

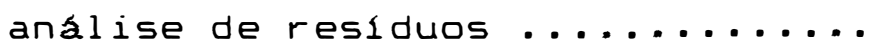


3.2. Limites de detecção, porcentagens de recuperaçăo e descrição do método de análise de residuos de clorpirifos e fenitrotion em casca e polpa de pepino ........

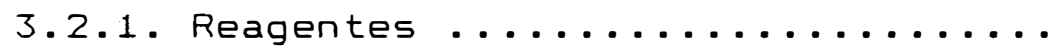

3.2.2. Aparelhos, vidrarias e outros ma-

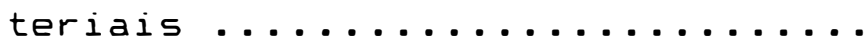

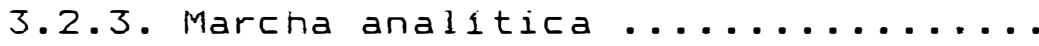

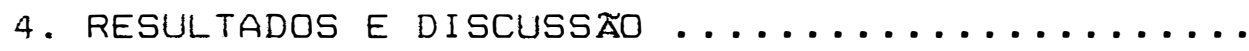

4.1. Limites de deteç̧ão e porcentagens de re-

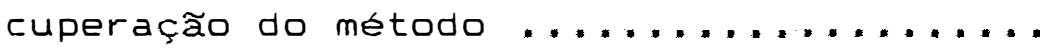

4.2. Residuos de clorpirifos em casca e polpa

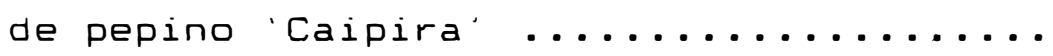

4.3. Residuos de fenitrotion em casca e polpa

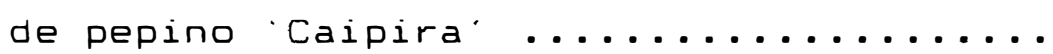


1 Curvas de degradaçăo (A) e persistência (B) idealizadas e ilustrativas, para inseticidas năo sistêmicos sobre e no interior de casca de laranja (GUNTHER,

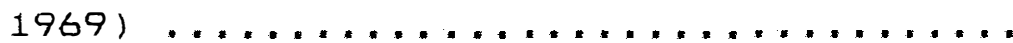

2 Formula estrutural do clorpirifos ......

3 Formula estrutural do fenitrotion .....

4 Foto mostrando o experimento onde foi realizado o presente trabalho .........

5 Cromatogramas do padrăo e da amostra de casca fortificada com 0,02 ppm de clor-

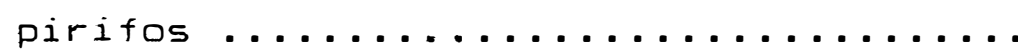

6 Cromatogramas do padrăo e da amostra de polpa fortificada com 0,02 ppm de clor-

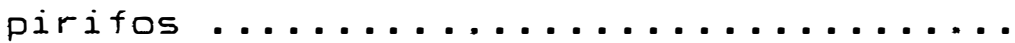

7 Cromatogramas de amostras testemunhas de casca e polpa. As setas indicam o "tempo de eluiçăo" de clorpirifos .........

8 Cromatogramas do padrăo e da amostra de casca fortificada em 0,02 ppm de fenitrotion ...................... 
vi i i.

FIGLRA No

Página

9 Cromatogramas do padrăo e da amostra de polpa fortificada com 0,02 ppm de feni-

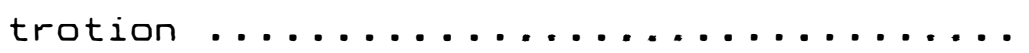

10 Cromatogramas de amostras testemunhas de casca e polpa. As setas indicam o "tempo de eluição" do fenitrotion ...........

11 Curvas de degradação de residuos de clorpirifos em casca de pepino 'Caipira' provenientes de plantas tratadas com 77 g i.a.l100 litros de água. 1a. pulverização (curva A), 2a. pulverização (curva B) $\ldots \ldots \ldots \ldots \ldots \ldots \ldots \ldots \ldots \ldots \ldots \ldots \ldots \ldots \ldots \ldots \ldots \ldots$

12 Curvas de degradação de residuos de clorpirifos em casca de pepino 'Caipira' provenientes de plantas tratadas com 144 g i.a./100 litros de água. 1a. pulverização (curva $A$ ), 2a. pulverização (curva B) $\ldots \ldots \ldots \ldots \ldots \ldots \ldots \ldots \ldots$

13 Curvas de degradação de residuos de fenitrotion em casca de pepino 'Caipira' provenientes de plantas tratadas com 150 g i.a./100 litros de água. 1a. pulverização (curva $A$ ), 2a. pulverização (curva

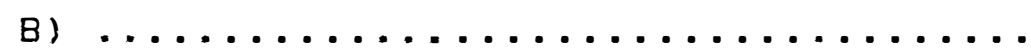


FIGURA N

14 Curvas de degradação de residuos de fenitrotion em casca de pepino 'Caipira' provenientes de plantas tratadas com 300 $g$ i.a.l100 litros de água. 1a. pulverização (curva $A$ ), 2a. pulverização (curva

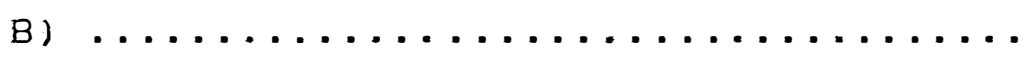


1 Porcentagens de recuperação de clorpirifos pelo método analítico empregado em casca e polpa de pepino 'Caipira'

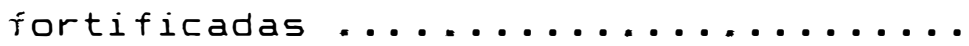

2 Porcentagens de recuperação de fenitrotion pelo método analitico empregado em casca e polpa de pepino Caipi-

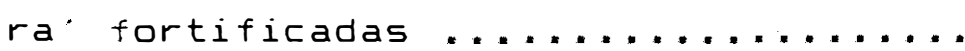

3 Residuos de clorpirifos em casca e polpa de pepino 'Caipira' provenientes de plantas tratadas com $77 \mathrm{~g}$ i.a.l 100 litros de água (tratamento A) e $144 \mathrm{~g}$ i.a.l100 litros de agua (tratamento B). 1a. pulverização .........

4 Residuos de clorpirifos em casca e polpa de pepino 'Caipira' provenientes de plantas tratadas com $77 \mathrm{~g}$ i.a.l100 litros de agua (tratamento A) e $144 \mathrm{~g}$ i.a./100 litros de agua (tratamento B). 2a. pulverizaçăo ............

5 Avaliações da espessura das cascas de pepino $(\mathrm{mm}) \ldots \ldots \ldots \ldots \ldots \ldots \ldots . \ldots . \ldots$ 
$x i$.

TABELA No

7

Residuos de fenitrotion em casca e polpa de pepino 'Caipira' provenientes de plantas tratadas com 150 g i.a./100 litros de água (tratamento A) e $300 \mathrm{~g}$ i.a.l100 litros de água (tratamento B). 1a. pulverização ............

8 Residuos de fenitrotion em casca e polpa de pepino 'Caipira' provenientes de plantas tratadas com 150 g i.a./100 litros de água (tratamento $A$ ) e $300 \mathrm{~g}$ i.a./100 litros de água (tratamento B).

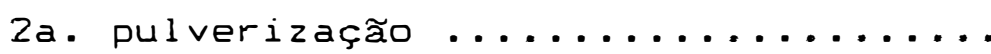


xi i .

RESIDUOS DE CLORPIRIFOS E FENITROTION EM CASCA E POLPA DE PEPINO 'CAIPIRA' DETERMINADOS POR CROMATOGRAFIA EM FASE GASOSA

Autor: João Cezar Ferst Orientador: Prof. Dr. Gilberto Casadei de Batista

\title{
RESUMO
}

\begin{abstract}
Neste trabalino foi estudado o comportamento dos residuos de clorpirifos (Lorsban $480 \mathrm{Br}$ ) e fenitrotion (Sumithion 500 CE) em casca e polpa de pepino.
\end{abstract}

0 experimento foi conduzido em campo experimental do Departamento de Entomologia da Escola Superior de Agricultura "Luiz de Queiroz" da Universidade de Săo Paulo, em Piracicaba-SP.

Os inseticidas foram pulverizados por ocasião da frutificação nas dosagens de 77 e $144 \mathrm{~g}$ i.a./100 litros de água, de clorpirifos, 150 e 300 g i.a.l100 litros de s.gua, de fenitrotion até a saturaçăo e escorrimento.

As pulverizações foram realizadas através de um pulverizador costal manual com um volume de aplicação de aproximadamente $500 \mathrm{litros} / \mathrm{ha}$. As amostragens foram realizadas aos 0,3 , e 8 dias após a primeira aplicação e aos 0,8 e 14 dias após a segunda, sendo que, as cascas e polpas foram analisadas separadamente. 
O método analítico empregado, para a análise dos residuos dos dois inseticidas em ambos os substratos, constou de extração com acetona, seguida de partição com diclorometano e concentração dos extratos. A determinação quantitativa foi realizada em cromatógrafo de gás, equipado com detector de ionização de chama alcalina (DICA).

Os limites de detecção obtidos para o método foram de 0,02 ppm para os dois inseticidas em ambos substratos. As porcentagens de recuperação variaram de 75 a $115 \%$ para clorpirifos e de 88 a $125 \%$ para fenitrotion.

Os residuas dos dois inseticidas nas cascas apresentaram uma rápida degradação, pois aos 8 dias após a aplicação os residuos de fenitrotion não foram detectados e, quando foram, ocorreram em niveis muito baixos, mas os residuos de clorpirifos foram detectados, ainda, aos 14 dias após a aplicação.

Os inseticidas apresentaram comportamento tipico de curva de degradação, sendo que os valores de meia-vida de degradação de clorpirifos nas cascas "variaram de 3-4 dias em ambas dosagens e nas duas aplicaçăes e as de fenitrotion foram de um dia nas duas dosagens e nas duas aplicaçỡes.

Não foram detectados residuos de clorpirifos na polpa, e os de fenitrotion, o foram em algumas amostras colnidas logo após a primeira aplicação em niveis de até 0,04 ppm. 
xiv.

Como os limites de tolerância para pesticidas em pepino são estabelecidos com base na fruta toda, sendo a tolerância do fenitrotion de 0,5 ppm e sua carência de 14 dias, os residuos não foram superiores à tolerância para a dosagem menor, ainda que logo após a aplicação, e na dosagem maior, 3 dias após a aplicação. 
$x v$.

CHLORPYRIFOS AND FENITROTHION RESIDUES IN 'CAIPIRA' CUCUMBER RIND AND PULP DETERMINED BY GAS CHROMATOGRAPHY

Author: Jo苂o Cezar Ferst Adviser: Prof. Dr. Gilberto Casadei de Batista

\section{SUMMARY}

Chlorpyrifos (Lorsban $480 \mathrm{Br}$ ) and fenitrothion (Sumithion 500 CE) residues behaviour in cucumber $r$ ind and pulp were reported.

The experiment was conducted in a field of the Department of Entomology at Escola Superior de Agricultura "Luiz de Queiroz", University of Săo Paulo, in Piracicaba, SP, Brazil.

The insecticides were sprayed during fruiting period at dosages of chlorpirifos 77 and $144 \mathrm{~g}$ a.i./100 1 water of and fenitrothion 150 and $300 \mathrm{~g} \mathrm{a.i./100} \mathrm{l}$ of to saturation run-off.

The sprayings were carried out by means of a manual back pack sprayer with an application volume of approximately 500 liters/ha.The samples were taken 0,3 and 8 days after the first application and 0 , 8 , and 14 days after the second application, with rinds and pulps being analyzed separately. 
$x v i$.

The analytical method employed for residue analysis of the insecticides, in both substrates involved extraction with acetone, followed by partition with dichloromethane and the extract concentration. The quantitative determination was carried out in a gas chromatograph apparatus, equipped with an alkaline flame ionization detector (AFID).

The detection limit obtained was 0.02 ppm for both insecticides in both substrates. The recovery percentages ranged from 75 to $115 \%$ for chlorpyrifos and from 88 to $125 \%$ for fenitrothion.

Both insecticides residues on the rind presented fast degradation; 8 days after application fenitrothion residues were not detected and, when they were, they occurred in very low levels; however, chlorpyrifos residues could still be detected 14 days after application.

Chlorpyrifos residues were not detected in to the pulp and fenitrothion residues were found in some of the samples collected immediately after the first application in levels of up to 0.04 ppm.

Since the tolerance limits for pesticides in cucumber are established in basis of the whole fruit, a $t 14$ days after last application (safety interval) fenitrothion residues were below legal tolerance level (0.5 ppm). 


\section{INTRODUÇÃO}

o desenvolvimento da agricultura, a ampliação das fronteiras agricolas e, principalmente, a exigência dos mercados para produtos de altissima qualidade visual, tem exigido um uso maciço de pesticidas, muito embora as produtividades năo acompanhem na mesma proporção esse crescimento.

Na produção intensiva de hortaliças é onde ocorrem principalmente grandes abusos quanto ao uso incorreto e intensivo desses insumos.

A gravidade do problema acentua-se devido ao fato de que muitas hortaliças são consumidas "in natura", sendo que a maior parte dos produtores desconhecem e/ou não respeitam os períodos de carência, realizando pulverizaçăes até a colheita.

Problemas de residuos de pesticidas, relacionados com a contaminação de alimentos e do meio ambiente, trouxeram preocupaçốes à entidades governamentais e à saúde pública, sobre o futuro no controle de pragas e doenças. 
o controle químico será ainda importante nas proximas décadas como um componente nos programas de controle de pragas, doenças e plantas daninhas, mesmo que apresentem riscos de contaminação ambiental e dos alimentos (GALLo et alii, 1988).

Ainda que necessarios, os pesticidas são também tóxicos e podem deixar residuos persistentes no alimento e no meio ambiente, podendo causar problemas \& saúde pública.

$$
\text { Segundo COBBE (1983), o Brasil exporta }
$$

aproximadamente, 11.600 toneladas anuais de hortaliças (morango, pepino, quiabo, tomate, etc.), rendendo em torno de US\$ 5.500.000,00/ano (media de 9 anos). As exportaçỡes podem aumentar se os produtos apresentarem boas qualidades no aspecto visual, bem como a presença de residuos de pesticidas a niveis aceitáveis.

Em algumas oportunidades a imprensa tem noticiado a recusa de paises importadores em aceitar partilhas de nossos produtos exportados por conterem residuos de pesticidas acima das tolerâncias internacionalmente aceitaveis, como ocorreu com uma partilha de carne e outra de fumo, anos atrás, contaminadas com inseticidas organoclorados. Um outro fato ocorreu com laranjas contaminadas com carbofenotion, recusadas pela Holanda.

No Brasil, freqüentemente a imprensa tem noticiado o problema de residuos nos alimentos, como ocorreu 
com morango no Rio Grande do Sul, maçã no Paraná e batata em São Paulo.

"A realização de pesquisas de persistência de residuos de agrotóxicos em alimentos, tornou-se necessária a fim de se conhecer os verdadeiros niveis de contaminação e, assim, fornecer subsidios para orientação de ações governamentais na área de saúde e prevenção dos possiveis problemas que poderiam advir desta contaminação" (FUNDAÇđ̃o CIENCIA E TECNOLOGIA - CIENTEC, 1986).

Este trabalho, vem procurar preencher uma lacuna na pesquisa com pesticidas no Brasil em plantas olericolas. Trabalhos similares já foram realizados em citros, fornecendo informaçzes importantes no que se refere ao uso e aspectos toxicológicos de determinados produtos na cultura em questão.

Dessa maneira, o presente trabalino tem como objetivos:

a) Estudar a degradação e persistência de residuos dos inseticidas clorpirifos e fenitrotion em casca de pepino;

b) Avaliar a possibilidade de penetração desses inseticidas para o interior da polpa dos frutos;

c) Determinar as curvas de degradaçăo e/ou persistência dos dois produtos nas cascas e suas respectivas meias-vidas; 
d) Correlacionar os niveis de residuos encontrados com os limites de tolerancia e os periodos de caréncia estabelecidos pela legislaçăo. 
5.

\title{
2. REVISÃO DE LITERATURA
}

\author{
2.1. Aspectos básicos no estudo de resíduos \\ de pesticidas
}

Para que um pesticida seja recomendado, năo basta que ele seja eficiente no controle de pragas, doenças ou plantas daninhas; ele deve ser seguro para os aplicadores em suas várias formulações e não deve deixar residuos prejudiciais nas partes comestiveis das plantas. Dessa maneira, devem ser encontrados meios de se usar esse pesticida de maneira que os residuos resultantes do tratamento não excedam à tolerância estabelecida pelos órgãos públicos competentes. Infelizmente, dados de residuos não podem ser extrapolados de uma cultura ou dosagem para outra, sendo que os dados detalhados de residuos săo necessários para cada cultura, pesticida, formulação e dosagem (EBELING, $1963)$.

Segundo GIANNOTTI (1971), o residuo poderia ser interpretado, a primeira vista, como uma simples camada de pesticida que recobre as folhas, frutos, ralzes, etc., 
das plantas depois da aplicação dos mesmos; tal camada, entretanto, deve ser considerada como deposito do material. Desde que esta camada venha a sofrer a ação dos fatores climaticos como chuva, sol, vento, etc., e o que fica absorvido em maior ou menor quantidade nas plantas é que deve ser considerado como residuo.

GUNTHER (1969) cita que os processos de degradação e persistencia geralmente seguem uma reação cinética de primeira ordem, permitindo dessa maneira, estabelecer uma relação linear entre o logaritmo do valor do residuo (em ppm) e os intervalos de tempo decorridos desde o tratamento.

De acordo com GUNTHER \& BLINN (1955), o perído requerido para o desaparecimento de uma certa porcentagem de residuos é independente da quantidade do depósito inicial; assim, a magnitude do depósito a uma certa data futura pode ser antecipada de acordo com a inclinação da curva ao tempo em que a extrapolação é feita. Isso é de grande importancia, pois possibilita o conhecimento da data aproximada em que os residuos alcançarão o nivel de toleráncia.

Em geral, quando o tratamento é realizado com um inseticida em aplicação convencional de pulverização ou polvilhamento, uma parte do depósito inicial perde-se de maneira mais rápida do que o restante. Nesse caso, o logarítmo da quantidade de residuos, em função do períado de 
exposição, produz uma curva do tipo da Figura 1 (GUNTHER, $1969)$.

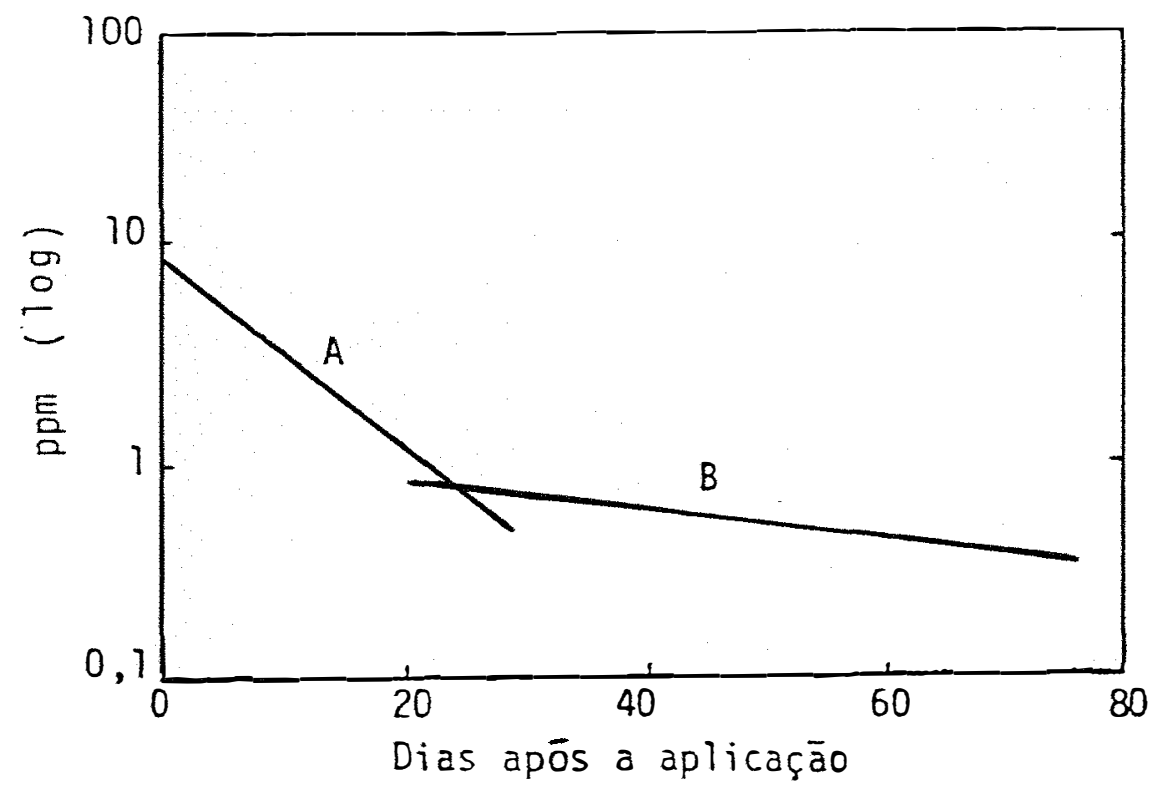

Figura 1. Curvas de degradação (A) e persistencia (B) idealizadas e ilustrativas, para inseticidas năo sistémicos sobre e no interior de cascas de laranjas (GUNTHER, 1969 ).

Os segmentos de retas designados por A e B foram chamados pelo autor como curvas de degradação e de persistência, respectivamente. A porção A da curva acusa uma rápida perda do depósito inicial dentro dos primeiros dias, como resultado da remoçăo do material não bem aderido à superficie vegetal principalmente pela açăo dos ventos e 
das chuvas. A porção B da curva mostra uma maior dificuldade na remoção dos residuos remanescentes, mais aderidos ao substrato vegetal; nesse caso a perda do residuo é quase, exclusivamente, dependente dos fatores da planta, principalmente enzimas que promovem a metabolismo do produto, especialmente através de hidrólise, reação com grupos SH, oxidação e outros (GUNTHER, 1969).

Devido ao envolvimento de reaçơes de primeira ordem, a periodo de "meia-vida", RLSO, que é a tempo necessärio para que haja desaparecimento da metade do residuo, é independente da concentração inicial, e assim representa a característica de cada produto sobre ou dentro de um substrato particular. Para cada segmento (A e B) da Figura 1 , tem-se uma meia-vida; estas são chamadas de meia-vida de degradação, ou depósito para a porção A (curva de degradação) e meia-vida de persisténcia ou de residuo para a porção B (curva de persisténcia) (GUNTHER, 1969).

Este mesmo autor cita que para um determinado produto e cultura, o valor de meia-vida de persistencia é uma caracteristica constante e utilizada em comparação de persisténcia (longevidade) de varios produtos e que as meias-vida, baseadas nas curvas de degradação, são muito afetadas pelas variações das condiçơes climaticas; assim, uma chuva no perído de degradação irá deslocar para baixo ambas as curvas, podendo alterar a inclinação da curva de degradação, mas não a de persistência. 
EBELING (1963) cita que alguns inseticidas em certas plantas atingem a tolerância durante a fase de degradação, enquanto que em outras plantas, os mesmos produtos atingem a tolerância na fase de persistência.

DUPUIS (1975) afirma que a formulação pode afetar a taxa e o grau de penetração do produto ou a tenacidade do depósito superficial, sendo que a penetração do produto pode aumentar a degradação se o composto atingir o tecido sub-cuticular com alta atividade metabolica. Porém, se o mesmo permanecer na cuticula mais ou menos inerte na folna ou fruto, pode persistir por um longo periodo protegido das influências externas.

- Alguns fatores que envolvem a degradação dos residuos, são a taxa de crescimento da planta, tipo de planta, penetração, translocação, oxidação, temperatura, volatilização e hidrólise. Em plantas que apresentam um rápido crescimento, este é o fator mais importante na dissipação dos residuos; os inseticidas do tipo p-nitrofeniltionofosfatos não apresentam, ou apresentam pouca penetração e a hidrólise de seus oxons são muito mais rápidas do que seus respectivos tionofosfatos e, isto, talvez, seja a razão pela qual é dificil se encontrar oxons dos tionofosfatos (COFFIN, 1964).

ROUCHAUD \& MEYER (1982) relatam que os pesticidas geralmente penetram nos tecidos da planta, mesmo que fracamente, sendo que os produtos que não penetram neles, 
permanecem na superficie da planta, sendo fotodecompostos, perdendo-se por volatilizaçăo e lavagem pelas chuvas.

Quanto a penetraçăo dos produtos, GUNTHER \& JEPPSON (1954) e GUNTHER \& BLINN (1955), distinguem tres categorias de residuos: extracuticulares, cuticulares e subcuticulares. Os primeiros săo aderentes à camada de cera; os segundos săo os residuos incrustrados ou dissolvidos nela e os últimos são aqueles presentes abaixo desta camada.

SPENCER ( 1965 ) afirma que a formulaçăo $\Leftrightarrow$ um dos fatores que mais afeta a taxa de degradação dos pesticidas, pois concentrados emulsionáveis penetram rapidamente nos tecidos das plantas e apresentam uma curva de residuos persistentes, enquanto que o pó molhável possui uma curva de degradaçăo e outra de persistencia.

A World Health Organization ${ }^{1}$, citada por PIZANO (1988), considera que altas dosagens ou multiplas aplicaçōes geralmente produzem altos niveis de residuos, isto é, a quantidade de residuos logo após a aplicação é proporcional a quantidade de ingrediente ativo aplicado.

- A presença de residuos em uma determinada amostra depende do tipo de produto utilizado, da estrutura e propriedades fisico-químicas de cada produto, do tipo de pulverização, época da pulverização, número de aplicaçত̃es,

1 WORLD HEALTH ORGANIZATION - WHO. Bromopropylate in: WHO evaluation of some pesticide residue in food. Geneva, 1974. p.62-91. (WHO Pesticide Residue Series, 3). 
periodo de carência, formulação do produto, condiçžses climáticas, morfologia e fisiologia da planta (DUPUIS, 1975).

Outros conceitos toxicológicos importantes do ponto de vista de residuos são: tolerăncia, intervalo de segurança e ingestão diária aceitável.

A toleráncia ou limite máximo de residuos é a quantidade máxima de residuos de um pesticida tolerada em um alimento, como decorrência de sua aplicação adequada, numa fase especifica desde a sua produção até o consumo, expressa em partes (em peso) do pesticida elou seus metabólitos por um milhão de partes (em peso) do alimento (ppm). Por intervalo de segurança ou perído de carência, entende-se "o intervalo de tempo, expresso em dias, entre a última aplicação do pesticida e a colneita ou comercialização do vegetal, abate ou ordenha do animal, conforme o caso, a fim de que os residuos estejam de acordo com os limites máximos permitidos". A ingestão diária aceitável "é a quantidade máxima de ingrediente ativo elou seus metabólitos que, ingerida diariamente durante toda a vida, parece não oferecer riscos apreciáveis à saúde, à luz dos conhecimentos atuais, e é expressa em mg do pesticida por kg de peso corpóreo (mg/kg)" (RESiduOS de defensivos..., 1984, citando a resolução n० $12 / 1974$ do Ministerio da Saúde). 


\subsection{Residuos de inseticidas em hortaliças e outras culturas}

As pesquisas sobre residuos de pesticidas no Brasil ainda são poucas, ficando limitadas a algumas análises de monitoramento coletadas em centrais de abastecimento como CEAGESP-SP, CEASA-RS, além de pesquisas realizadas principalmente na ESALQ/USP-Piracicaba e ESAL-Lavras relacionadas com a degradação e persistência deles. Os resultados indicam que as contaminaçŏes são baixas, sendo que as mais importantes, são por pesticidas que não apresentam registro para as respectivas culturas (CIENTEC, 1986; UNGARO et alii, 1980; UNGARO et alii, 1987).

\subsubsection{Residuos de clorpirifos em algumas culturas}

LEUCK et alii (1968) estudaram a dissipação de clorpirifos em capim bermuda e milho forrageiro. 0 inseticida foi aplicado na dosagem de $1120 \mathrm{~g} \mathrm{i.a./ha.} \mathrm{As} \mathrm{amos-}$ tragens foram realizadas aos $0,1,2,4,7,14$ e 21 dias, após a aplicação, e os depósitos encontrados na primeira amostragem foram de 13,2 e 5,60 ppm para o capim bermuda e o milho, respectivamente; na segunda amostragem houve uma redução dos residuos para 7,38 e 3,46 ppm nas respectivas culturas e, com dois dias após a aplicação, os niveis encontrados foram de 4,30 e 2,42 ppm. Os autores detectaram, 
ainda, residuos até 24 dias, após a aplicação, de 0,18 ppm em capim bermuda e de 0,42 ppm, aos 14 dias mo mil ho.

Análises de residuos de clorpirifos em alface foram realizados por MAINI et alii (1972). As dosagens utilizadas na pulverização foram de 100 e 500 g i.a./ha. As amostragens foram realizadas na ocasião da colheita, aos 14 dias após o tratamento. Os estudos de recuperação em amostras fortificadas com $0,02 \mathrm{ppm}$ de clorpirifos indicaram recuperação de cerca de $65 \%$, fazendo-se extração com acetonitrilo, partição com águaléter de petróleo, limpeza em coluna de florisil e determinação em cromatógrafo de gás equipado com detector termaiônico. Os miveis de residuos encontrados nas amostras, foram de 0,07 e 0,046 ppm para as dosagens de 100 e 500 g i.a./ha, respectivamente. As análises foram realizadas para se determinar apenas clorpirifos e não seus produtos de degradação (análogos oxigenados), devido ao não aparecimento de menhum pico nos cromatogramas que acusassem a presença destes outros componentes.

$$
\text { BRAUN et alii (1975) analisaram os residuos }
$$
de clorpirifos em alface, cebola e cenoura, sendo que foram realizadas três aplicaçơes, utilizando-se as dosagens de 144, 288 e 432 g i.a./ha. A primeira aplicação foi realizada antes da semeadura, a segunda logo após a emergência e a terceira 15 dias após a segunda. O volume de aplicação foi de 675 l/ha. As análises foram realizadas por cromatografia 
gasosa com detector fotometrico de chama. A porcentagem média de recuperação foi de 92, 87 e 93\% para alface, cebola e cenoura, respectivamente, utilizando-se acetonitrilo para extração e partição com hexano. As colheitas foram realizadas 39, 104 e 131 dias após a última aplicação para as respectivas culturas. Os mais altos valores de residuos encontrados foram de 0,019 ppm para alface; 0,01 ppm para cebola e 0,032 ppm para cenoura, todos referentes à dosagem de 432 g i.a./ha. Os autores analisaram, também, o análogo oxigenado, o qual năo foi detectado em nenhuma amostra.

IWATA et alii (1985) estudaram a degradação e persisténcia de clorpirifos em laranjas, onde realizaram uma aplicação de $1.680 \mathrm{~g}$ i.a./ha com um volume de aplicação de936 litros/ha; 32 dias após realizaram outra aplicação na dosagem de $6.720 \mathrm{~g}$ i.a./ha. As frutas maduras foram amostra- das $31,35,38,41$ e 45 dias após a última aplicação e foram encontrados os seguintes niveis de residuos, respectivamente: 3,$1 ; 2,0 ; 1,3 ; 1,2$ e $1,1 \mathrm{ppm}$; quando plotados em escala semilogaritmica o inseticida apresentou curvas de degradação e de persisténcia e os valores de meia-vida de degradação e de persistência foram de 2,5 e 64 dias, respectivamente.

No periodo compreendido entre 1982 e 1986 LUKE et alii (1988) analisaram 19.851 amostras de alimentos produzidos nos Estados Unidos ou importados; os resultados mostram que os inseticidas metamidofos e clorpirifos săo os 
que tiveram maior incidencia, pois foram detectados em 4.764 e 1.969 amostras, respectivamente. Fenitrotion e seu análogo oxigenado não foram detectados em nenhuma amostra. Ds autores informam ainda que $75 \%$ das amostras que violaram a legislação são aquelas que apresentam produtos não registrados para a respectiva cultura. Os mesmos autores analisaram 1.326 amostras de pepino para salada e conserva e encontraram 320 amostras com residuos de clorpirifos, sendo que 54 foram consideradas contaminadas; pois estavam com o nivel de residuo acima da toleráncia permitida pela legislaçăo americana.

\subsubsection{Residuos de fenitrotion em algumas culturas}

LEUCK et alii (1971) estudaram os residuos de fenitrotion bem como seus metabólitos fenitrooxon e 4-nitrom-cresol em silagem de milho. As dosagens utilizadas foram de $1.120,2.240$ e $3.360 \mathrm{~g}$ i.a./ha. Após 128 dias de ensilagem, houve uma redução dos depósitos de 4,47; 11,4 e 16,6 ppm dos respectivos tratamentos para 3,41; 6,49 e 9,50 ppm e não foram detectados residuos de fenitrooxon, mas o de 4-nitro-m-cresol foi encontrado.

JOIA \& KALRA (1974) estudaram a persistência de endossulfan, fenitrotion, fention e malation em quiabo, pulverizados em ultra-baixo-volume nas dosagens de 150; 150; 100 e 250 g i.a./ha, respectivamente. Os depósitos iniciais 
foram de 0,$16 ; 0,14 ; 0,22$ e 0,22 ppm para os respectivos inseticidas. Os autores observaram que a taxa de desaparecimento dos inseticidas foram elevadas, pois $44 \%$ de endossulfan, $71 \%$ de fenitrothion, $32 \%$ de fention e $64 \%$ de malation dissiparam-se em 1 dia; no segundo dia a dissipação foi de 56, 90, 68 e 91\% para os respectivos inseticidas. A recuperação dos inseticidas endossulfan, fenitrotion, fention e malation em fortificaçöes de 0,1 ppm foram de 89,$5 ; 84,3 ; 70,7$ e 85,4\%, respectivamente. A extração foi realizada com acetonitrilo, sendo, depois, realizada uma partição com éter de petróleo e determinação quantitativa atraves de cromatografia gasosa com detector de ionização de chama.

RIGITANO (1979) estudou a penetração de fenitrotion na polpa atraves da casca de laranjas e observou que não houve penetração a nivel de 0,05 ppm (limite de deteç̧ão do método analitico) na dosagem utilizada de 75 g i.a./100 litros de água e os residuos persistiram na casca até 104 dias após a aplicação a nível de 0,45 ppm. o método utilizado foi modificado daquele de MOLLHOFF (1967) que consiste em extração com acetona e partiçăo com cloroformio, e limpeza em coluna de florisil. A análise quantitativa foi realizada em cromatógrafo de gás equipado com detector de ionização de chama alcalina.

Estudos com fenitrotion em couve-flor e repoIhos foram conduzidos por HANDA et alii (1989). Os autores 
17.

aplicaram as dosagens de 500 e 1000 g i.a./ha. As amostras foram colhidas aos $0,7,15$ e 20 dias depois do tratamento. A extração foi feita com clorofórmio e a determinação por colorimetria. Os estudos de recuperação foram feitos nos níveis de 5 e 10 ppm, obtendo-se uma recuperação de 85 e $90 \%$ para couve-flor e repolho, respectivamente. Os depósitos iniciais em couve-flor foram de 4,0 e 11,20 ppm para as duas dosagens, respectivamente; 7 dias após houve uma redução de 60,1 e $54,1 \%$ nos residuos nas respectivas dosagens e aos 15 dias após a aplicação a dissipação dos residuos foram da ordem de 98,75 e $99,01 \%$. Os valores de meias-vida foram de 2,2 e 2,8 dias para 500 e 1.000 g.ia/ha, respectivamente. Em repolho, os niveis iniciais foram de 3,6 ppm para a dosagem mais baixa e 8,0 ppm para a mais alta. A redução dos residuos aos 7 dias foi da ordem de 69,4 e $67,5 \%$ e aos 15 dias de 99,4 e $97,5 \%$. Os autores ainda comentam que uma lavagem e fervura reduzem os niveis de fenitrotion em 80 e 86\% dos depósitos, logo após a aplicação das duas dosagens estudadas.

$$
\text { AL-SAMARRAIE et alii (1989) estudaram }
$$

residuos de clorpirifos e fenitrotion em tâmaras. A formulação comercial foi pó na concentração de 20 e 10 g i.a./kg dos respectivos produtos. Os produtos foram diluidos em farinha de trigo a uma concentração de 5 ppm para serem polvilhados. As colheitas foram realizadas aos 0,10 e 90 dias após a aplicação. Os estudos de recuperação com amos- 
tras fortificadas com 0,01 e 0,05 ppm apresentaram recuperaçăo acima de $84 \%$ Os depósitos iniciais de clorpirifos e fenitrotion foram de 1,9 e 3,9 ppm, sendo que, após 10 dias esses niveis foram reduzidos para 0,4 e 0,2 ppm, respectivamente, ou seja uma redução de 79 e $95 \%$ nos residuos de clorpirifos e fenitrotion. Aos 90 dias os residuos encontrados foram de 0,005 e 0,006 ppm.

\subsection{Amostragem para análise de residuos de pesticidas}

A resolução $n^{\circ} 12 / 74$ da antiga Comissão $\mathrm{Na}-$ cional de Normas e Padrões para Alimentação (CNNPA) do Ministério da Saúde, estabeleceu as normas sobre a quantidade e condiçơes das amostras para análise de residuos de pesticidas. Para pepino, que é classificado como hortaliça, não folhosa, a quantidade mímima é de $2,0 \mathrm{~kg}$ sem o pedúnculo, mas permanecendo as sementes e casca, ainda, as amostras devem ser acondicionadas em vidros revestidos internamente com papel aluminio, sacos de papel novos e fortes e papel aluminio, sendo que não se deve usar plástico para o acondicionamento (RESIDUOS de defensivos..., 1984).

AMBRUS (1983) sugere que a quantidade minima para amostragem de produtos agricolas de tamanhos relativamente grandes como pepino, melão e repolho, destinados à análise de residuos, seja de pelo menos 5 unidades e no mínimo de $2,0 \mathrm{~kg}$ de peso. 


\subsection{Caracteristicas da cultura e problemas com pragas}

o pepino, Cucumis sativus L., é originário da India, sendo cultivado há mais de 4.000 anos e apreciado em todo o mundo. É uma cultura de clima quente, tolerando temperaturas amenas. Em localidades de baixa altitude podese semear ao longo do ano todo; em altitudes maiores, semeia-se de agosto a abril e é exigente em adubação para se obter boas produtividades (FILGUEIRA, 1987).

No ano de 1989 foram comercializadas no CEAGESP-SP mais de 1.700 .000 caixas $(24 \mathrm{~kg})$ de pepino, totalizando-se um valor de mais de Cr\$ 870.000.000,00, 口 que coloca a cultura em 40 lugar entre as hortaliças de maior importåncia económica naquele estabelecimento (BOLETIM ANUAL CEAGESP, 1989).

COSTA et alii (1961) em observaçöes de oito anos na região de Campinas-SP, dos danos causados pelas moscas minadoras de fol has nas culturas, comprovaram efeitos mais expressivos em batatinha, pepino, beterraba, acelga e couve-chinesa. Ainda, a importancia desses dipteros tem aumentado de ano para ano. Das especies presentes na regiăo, duas são mais frequientes, Liriomyza strigata e Liriomyza sp. (Diptera, Agromyzidae).

O minador L. Sativae Blanchard, 1938, nos últimos 10 anos, tem-se tornado a principal praga do pepino e de outras olericolas. Os seus danos caracterizam-se pela 
formação de galerias no mesófilo foliar, causando redução na área fotossintética, murcha e secamento das folhas (SHARMA et alii, 1980), pelas picadas alimentares e na oviposiça pela introdução do ovipositor nas folhas (JOHNSON et alii, 1980; MORAES et alii, 1981; DATMAN \& MICHELBACHER, 1959; POE et alii, 1978; TRYON et alii, 1980).

GROPPO (1981) relata que a praga L. sativae se encontra disseminada por todo o Estado do Rio de Janeiro, Espirito Santo e São Paulo, atacando várias olericolas, causando sérios prejuizos.

O minador L. sativae é praga das culturas de feijão, batata, ervilha, tomate, repolho, melancia, pepino, entre outras, e os inseticidas triclorfon, metamidofos e azinfos etil apresentam bom controle sobre a praga (GROPPO, $1981)$.

CAMPOS \& TAKEMATSU (1982) citam, em seus estudos, que a ocorrência de $L$. huidobrensis Blanchard, 1926, sobre diversas culturas no Estado de Săo Paulo, é responsável por prejuizos ocasionados em cucurbitáceas, solanáceas, leguminosas e cruciferas.

BARBOSA (1984) cita que o controle de pragas com piretróides sintéticos apresentam ótimos resultados contra algumas pragas de hortalicas como lagarta rosca, vaquinhas, traças e broca das frutas, mas não apresentam bom controle de insetos sugadores e minadores de folhas, sendo necessário o uso de organofosforados ou carbamatos. 
Os produtos organofosforados como etion, malation, fenitrotion, diazinon, acefato, paration, fentoato e muitos outros são os produtos mais largamente utilizados na produção de hortaliças no Brasil (BARBOSA, 1984).

FRANÇA et alii (1985) estudaram o controle da broca das cucurbitáceas Diaphania nitidalis (Cramer, 1782) (Lepidoptera, Pyralidae) e D. hyalinata (L., 1758) em pepino com avermectin 1,8 CE, Arrivo 20 CE, Sumition 50 CE, Thiobel 50 PS, Sumicidin 20 CE, Dipterex 50 CE, Naled-8E 86 CE, Pounce 38,4 CE, Orthene 75 PS, Thiodan 35 CE, Malatol 50 CE, Dipel PM, Sevin 85 PM, FMC 653185.6 CE, Baythroid 5 CE, Decis 2,5 CE, HOE $52215 \mathrm{CE}$, não sendo encontradas diferenças significativas entre os produtos testados.

SASSAKI \& KIMOTO (1986) testaram os inseticidas piretróides esfenvalerate nas dosagens de 50, 100, 150 e $200 \mathrm{ml} / 100$ litros de água, além de deltametrina na dosagem de $30 \mathrm{ml} / 100$ litros de água e fenvalerate com $75 \mathrm{ml} / 100$ litros de água, para controle da broca dos frutos, Diaphania spp., do pulgão Aphis gossypii Glover, 1877 (Hemiptera: Aphididae) e do ácaro Tetranychus spp. (Acari: Tetranychidae) na cultura do pepino; os resultados não apresentaram diferenças significativas entre si, todos mostrando um bom controle.

Para o controle de D. nitidalis, na cultura do pepino, LORINI \& FOERSTER (1987) testaram os seguintes inseticidas e respectivas dosagens em g i.a./100 litros de 
água: permetrina 10 (Ambush 50 CE); permetrina 10 (Pounce 384 CE); acefato 56,25 (Orthene 75 PS); cartap 75 (Thiobel 50 PS); etion 50 (Ethion 50 CE); deltametrina 1, O (Decis 2,5 CE); metomil 43 (Lannate); clorpirifos 48 (Lorsban $480 \mathrm{Br}$ ) e aldicarb (Temik 10 G) $1000 \mathrm{~g}$ i.a./ha, aplicado no solo. Os inseticidas acefato, clorpirifos e metomil foram os que apresentaram os melhores resultados para o controle da broca; citam ainda que a broca e a principal praga da cultura do pepino na atualidade, pois ataca diretamente os frutos.

Segundo GALLO et alii (1988) a cultura do pepino, juntamente com outras cucurbitáceas, são atacadas por diversas pragas como Diabrotica speciosa (Germ., 1822) (Coleoptera, Chrysomelidae), D. nitidalis (Cramer, 1782), D. hyalinata (L., 1758), A. gossypii Glover, 1877 e Anastrepha grandis (Macquart, 1845) (Diptera, Tephritidae) e, para o controle, recomendam o uso de inseticidas organofosforados, carbamatos e piretroides.

SCARPELLINI (1989) afirma que os cultivas de pepino no outono sofrem redução de 44\% na produção, quando a desfolha atinge $25 \%$ aos 45 dias após a germinação e, aos 15 dias após a germinação, mesmo com desfolhamento inferior à $25 \%$, a redução na produção é de $51 \%$.

VILLAS BOAS (1989) comenta que o controle das pragas através de produtos quimicos é atualmente o método de controle mais usado em hortaliças, sendo muito dificil o 
cultivo destas na forma intensiva, sem o uso destas subståncias, ainda que tentiam sido desenvolvidos grandes esforços na última década buscando-se métodos alternativos.

Os frutos de pepino, apresentam um rápido desenvolvimento, como mostra DEMATTé (1978) que estudou várias cultivares de pepino e, em média geral, observou que em apenas 3 dias, os frutos podem dobrar de peso, dependendo da época do ano, condições climáticas, nutrição das plantas e seu estágio de desenvolvimento.

\section{4. Clorpirifos}

E um inseticida organofosforado com modo de ação de contato, ingestão, fumigação e profundidade cujo nome químico é 0,o-dietil-0-3,5,6-tricloro-2-piridila tionofosfato.<smiles>CCOP(=S)(OCC)Oc1nc(Cl)c(Cl)cc1Cl</smiles>

Fórmula bruta: CaHsicl303NPS

Figura 2. Fórmula estrutural do clorpirifos.

o produto técnico tem a forma de cristais brancos; é solúvel em acetona, benzeno e clorofórmio, den- 
tre outros solventes orgânicos; é insolúvel em água, sendo estável em condiçơes normais de armazenamento. Para ratos albinos, sua DLso oral é de 170 a $220 \mathrm{mg} / \mathrm{kg}$ e a dérmica de $225 \mathrm{mg} / \mathrm{kg}$ de peso corpóreo; em camundongos, sua absorção pela pele é insignificante (MARICONI, 1988). A pressão de vapor é de $1,87 \times 10^{-5} \mathrm{mmHg}$ a $25 \circ \mathrm{C}$ e $8,15 \times 10^{-5} \mathrm{mmHg}$ a $35 \circ \mathrm{C}$ (GRAY, 1965) e sua ingestão diária aceitável de $0,01 \mathrm{mg} / \mathrm{kg}$ de peso corpóreo/dia (FAO/WHO citado por GARTRELL et alii, 1986).

CAVERO (1985) cita que clorpirifos é um bom produto para controle de ácaros, cigarrinhas, pulgões, lagartas, percevejos, coleópteros, carrapatos e moscas.

GELMINI \& NOVO (1987) citam a Portaria da Secretaria Nacional de Vigilância Sanitária (SNVS) n० 10 de 8 de março de 1985, que estabelece o limite máximo de seus residuos de clorpirifos para a cultura do tomate em 0,5 ppm e para couve em 1 , 0 ppm e um periodo de carência de 21 dias para ambas as hortaliças.

SMITH (1966) estudou a degradaçăo de clorpirifos em vegetais e observou que 75 a $80 \%$ do produto desaparece da superficie das folhas em 48 horas e que menos de 1\% do produto é absorvido e translocado pela planta. Em estudos sobre a degradação por luz ultra-violeta o autor acrescenta que em condições de campo, há uma degradação total do inseticida clorpirifos e de seus metabólitos a que - produto é mais estável à radiação ultra-violeta, quando 
estiver em meio seco e, embora tenha uma pressão de vapor baixa, o composto desaparece rapidamente, pois em solução de acetona sobre papel filtro, houve volatilização de $83 \%$ do produto em apenas trếs dias.

MEIKLE et alii (1983) estudaram a fotodecomposição de clorpirifos em solução aquosa e sobre superficie de papel filtro revestido por cera, e conclusram que em solução aquosa, a degradação do produto dá-se através de reaçăes combinadas de fotólise e hidrólise, e que o desaparecimento de clorpirifos seque como uma reação cinetica de primeira ordem em diferentes valores de pH. Nos estudas sobre a decomposição em papel de filtro, a degradação também seguiu uma reação cinética de primeira ordem e a meia-vida foi de 3,1 dias nos estudos de fotodecomposição e 7,8 horas para volatilização a $25^{\circ} \mathrm{C}$.

\subsection{Fenitrotion}

E um inseticida organofosforado com modo de ação de contato, ingestão e profundidade, cujo nome quimico é o,o-dimetil a-(4-nitro-m-tolil) tionofosfato.<smiles>COP(=S)(OC)Oc1ccc([N+](=O)[O-])c(C)c1</smiles>

Fórmula bruta: CoH12OsNPS

Figura 3. Formula estrutural do fenitrotion. 
o produto técnico é um liquido amarelo com tonalidade marrom; sua solubilidade em água a $30^{\circ} \mathrm{C}$ é de 14 mg/litro; apresenta alta solubilidade em diclorometano, metanol e xileno; é hidrolizado em condições alcalinas, possuindo uma meia-vida de 4,5 horas em uma solução $10 M$ de $\mathrm{NaOH}$. Sua DLso oral para ratos albinos fémeas é de 800 mg/kg, sendo de baixa toxicidade para mamiferos (JAPAN PESTICIDE INFORMATION, 1987). Sua pressão de vapor e de $5,4 \times 10^{-5} \mathrm{mmHg}$ a $20 \circ \mathrm{C}$ (HASSAL, 1982), e a ingestão diária aceitável é de $0,001 \mathrm{mg} / \mathrm{kg}$ de peso corpóreo/dia (FAO/WHO citado por GARTRELL et alii, 1986).

CAVERO (1985) cita que fenitrotion e utilizado para controle de aleirodideos, cochonilhas, cigarrinhas, coleópteros, lagartas, pulgơs, tripes e ácaros.

A mesma Portaria que regulamentou o uso de clorpirifos para tomate e couve, regulamentou, também, o fenitrotion para cucubitaceas estabelecendo o limite máximo de residuos de 0,5 ppm e um periodo de carencia de 14 dias. GREENHALGH \& MARSHALL (1976) estudaram a degradação de fenitrotion por irradiação ultravioleta e a meia-vida em hexano foi de 85 minutos e de 7 minutos em água e encontraram, como principal metabólito, o fenitrooxon. Citam também que a taxa de decomposição varia com o solvente. 


\section{MATERIAIS E METODOS}

\subsection{Experimento de campo}

o experimento foi conduzido no campo experi-

mental do Departamento de Entomologia da Escola Superior de Agricultura "Luiz de Queiroz" da Universidade de Săo Paulo, em Piracicaba-SP (Figura 4).

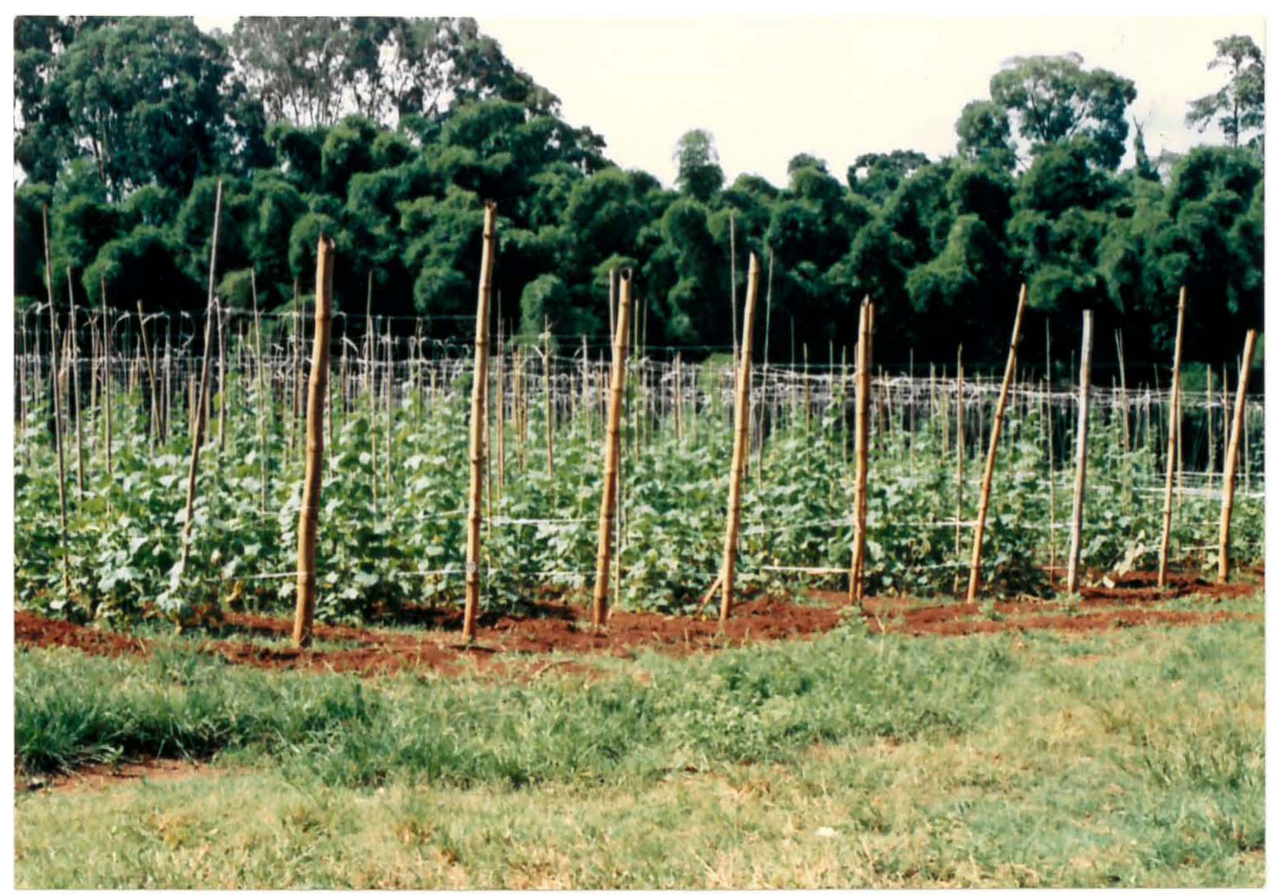

Figura 4. Foto mostrando o experimento onde foi realizado o presente trabalino. 


\subsubsection{Semeadura e tratos culturais}

A semeadura foi realizada dia 31 de janeiro de 1990 em covas com espaçamento de $1,0 \times 0,5 m$. Foi utilizado a cultivar de pepino 'Caipira' e conduzido no sistema tutorado. 0 experimento contou com 15 parcelas de $25 \mathrm{~m}^{2}$ cada uma e uma população de 50 a 60 plantas/parcela.

Foram realizadas adubaçơes na cova de plantio com 100 da fórmula 4-16-8 de NPK e duas aplicaçớs em cobertura com sulfato de amónio (10g/planta) no raleamento e no inicio da formação dos frutos.

Para o controle das doenças fúngicas, como o mildio (Pseudoperonospora cubensis), foram realizadas aplicações dos seguintes fungicidas: Benomil a $70 \mathrm{~g}$ P.c./ha e Ridomil + Mancozeb a 3009 de P.c./100 litros de água, a cada três dias, a partir do aparecimento dos sintomas.

Não houve ataque de pragas durante a fase vegetativa, mas na fase reprodutiva, houve um pequeno ataque de Diaphania spp.

\subsubsection{Pulverização dos inseticidas para análise de residuos}

Foram aplicadas 2 dosagens de cada inseticida com 3 repetiçơes para cada tratamento (dosagem), a saber: clorpirifos (Lorsban $480 \mathrm{Br}$ ) 77 e $144 \mathrm{~g}$ i.a.l100 litros de 
água e fenitrotion (Sumithion 500 CE) 150 e 3009 i.a./100 litros de água. O volume de calda aplicado foi cerca de 500 l/ha (até o inicio de escorrimento).

Realizou-se duas aplicaçōes: a primeira dia 26 de março de 1990 e a segunda 10 dias após a primeira. As pulverizaçōes foram realizadas através de pulverizador costal manual marca Jacto, com capacidade para 20 litros, utilizando-se, bico cônico vazio Dz-23.

As colheitas foram realizadas 0,3 e 8 dias após a primeira aplicação e 0,8 e 14 dias após a segunda, totalizando-se 6 colheitas. O total de amostras analisadas foram de 180 , a saber: 2 inseticidas $\times 2$ dosagens $\times 3$ repetiçơes $\times 2$ substratos (casca e polpa) $\times 6$ colheitas $=144$ amostras, além de 36 amostras testemunhas $=180$ amostras.

Cada amostra foi constituida por 15 frutos com um peso entre 2,5 e 4,0 kg (AMBRUS, 1983; RESiduOS de defensivos..., 1984). Em seguida à colheita, procedeu-se o descascamento dos frutos com uma faca comum e separadas as cascas das polpas; em seguida ambos os substratos foram cortados em pequenos pedaços, homogeneizados e pesadas sub-amostras de 100 gue foram acondicionadas em papel alumínio, identificadas e colocadas em "freezer" a $-18^{\circ} \mathrm{C}$ até - momento de serem preparadas para a análise.

Avaliou-se também a espessura da casca e para tanto, foi utilizado um paquímetro, tomando-se 100 amostras ao acaso para se obter a espessura média. 
Como as tolerâncias em pepino são estabelecidas com base na fruta toda, foi realizado também a pesagem das cascas e polpas, em separado, para se obter a porcentagem de cada um desses substratos, nos frutos.

Quanto as condiçơes climáticas, houve uma precipitação pluviométrica de $7,2 \mathrm{~mm}$ um dia após a primeira aplicação. As temperaturas nos horários das aplicaçơes foram de 27 e $28{ }^{\circ} \mathrm{C}$ na primeira e segunda aplicação, respectivamente. A temperatura máxima ocorrida após ambas as aplicaçơes foram $33^{\circ} \mathrm{C}$, minima de $15 \circ \mathrm{C}$ e a temperatura média em torno dos $25^{\circ} \mathrm{C}$.

Com relação a insolação, com exceção do dia posterior à primeira aplicação em que o sol permaneceu encoberto, nos dias restantes, a presença do sol foi constante.

3.2. Limites de deteç̧ão, porcentagens de recuperação e descrição do método de análise de resíduos de clorpirifos e fenitrotion em casca e polpa de pepino

A fim de se estudar os limites de deteç̧ão e as porcentagens de recuperação de clorpirifos e fenitrotion em casca e polpa de pepino 'Caipira', pelo método analitico empregado, amostras preparadas identicamente àquelas provenientes das plantas tratadas foram fortificadas a fim de se obter concentraçöes de 1;0,1;0,05;0,02;0,01 e 0,005 
ppm para clorpirifos e fenitrotion em ambos as substratos, sendo que as determinações foram feitas em duplicata para cada nível de fortificação. O método analitico basicamente consta de extração com acetona; em seguida é feita uma partição com diclorometano e concentração. Segue-se a determinação quantitativa feita em cromatógrafo de gas equipado com detector de ionização de chama alcalina (DICA).

\subsubsection{Reagentes}

- acetona - PA - ACS, destilada em destilador de vidro;

- diclorometano - PA - ACS, destilado em destilador de vidro;

- padräes analiticos de clorpirifos e fenitrotion;

- sulfato de sódio anidro.

\subsubsection{Aparelhos, vidrarias e outros materiais}

- cromatógrafo de gás CG-modelo 3700, equipado com detector de ionização de chama alcalina (DICA);

- coluna cromatográfica - vidro, diámetro de $1 / 8^{\prime \prime}$, com comprimento de $1,8 m$ e empacotada com 5\% DC 200/chrom. W, Aw-DMCS; 
- evaporador rotativo a vácuo - marca Büchi;

- homogeneizador (desintegrador) de alta rotaఢ̧ăo;

- bomba pneumática - marca GE (1/4 HP);

- micro-seringa $(10 \mu l)$ - marca Hamilton;

- frascos redondos $500 \mathrm{ml}$, 5 24/40;

- funil de separaçăo, Squib, de 500 ml com torneira de teflon;

- funil de Büchner - 100 mm de diămetro;

- quitassato, 500 ml de capacidade;

- adaptador de borracha para funil Büchner quitassato, $500 \mathrm{ml}$;

- provetas graduadas - 100, 250 e $500 \mathrm{ml}$;

- pipetas graduadas: 1, 2, 5 e $10 \mathrm{ml}$;

- tubos de centrifuga graduados - $15 \mathrm{ml}$;

- Papel de filtro Whatman $n^{\circ} 5$;

- rolhas de borracha;

- papel aluminio.

\subsubsection{Marcha analitica}

\section{a) Extração}

a.1) pesar 100 go material a ser analisado (cascas ou polpas), juntar $200 \mathrm{ml}$ de acetona e homogeneizar por trés minutos; 
a.2) filtrar em funil de Büchner através de papel de filtro com auxilio de vacuo;

a.3) lavar os conteúdos do copo do homogeneizador e os do funil de Büchner, mais duas vezes, com aliquotas de $50 \mathrm{ml}$ de acetona;

a.4) tomar metade do filtrado como aliquota, correspondente a 509 de material e transferi-la para um funil de separação de $500 \mathrm{ml}$, juntar $100 \mathrm{ml}$ de diclorometano, agitar vigorosamente por 30 segundos e deixar em repouso até a separação das fases. Repetir mais duas vezes esta operaçăo, com $30 \mathrm{ml}$ de diclorometano cada vez. Receber a fase orgänica inferior em balão de fundo chato de $500 \mathrm{ml}$, limpo, através de um funil com cerca de $50 g$ de sulfato de sodio anidro para reter a água que o extrato possa conter;

a.5) evaporar em evaporador rotativo a vácuo em banho-maria a 55-65०C ate aproximadamente, 2 a $5 \mathrm{ml}$; evaporar o solvente remanescente com auxilio de vácuo. 


\section{b) Determi nação quantitativa}

b.1) diluir as residuos provenientes de a.5, lavando o frasco redondo com exatamente $5 \mathrm{ml}$ de acetona e recolher em tubo de centrifuga graduado;

b.2) injetar al iquotas no cromatógrafo;

b.3) condiçâses de operação do cromatógrafo: coluna: vidro, comprimento $1,8 \mathrm{~m}$, diâmetro 1/8", fase liquida DC 200$5 \%$, suporte chromosorb $W$, AWDMCS;

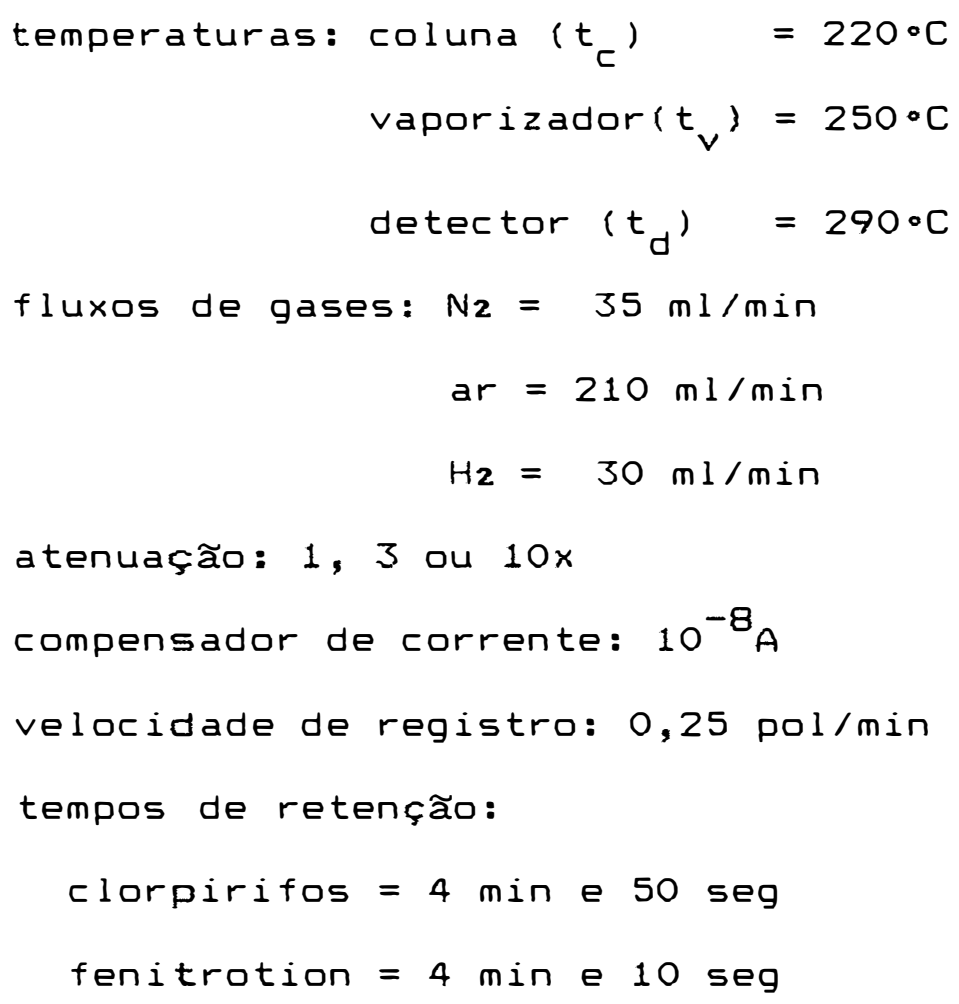




\section{b.4) cálculo dos residuos: os residuos foram calculados por comparação direta com os padrb̆es, baseados nas alturas dos picos dos padröes e das amostras.}

$$
\text { residuos em ppm }=\frac{m_{p} \times H_{a}}{H_{p} \times 10 V_{i}}
$$

onde:

$$
\begin{aligned}
& m_{p}=\text { massa injetada do padrăo em ng; } \\
& H_{a}=a l t u r a \text { do pico da substancia na amostra em } \mathrm{mm} \text {; } \\
& H_{p}=\text { altura do pico da substancia no padrão em mm; } \\
& v_{i}=v o l u m e \text { da injeçăo da amostra em } \mu l \text {. }
\end{aligned}
$$




\section{RESULTADOS E DISCUSSÃ̃o}

4.1. Limites de deteç̧ão e porcentagens de recuperação do métodó

Us resultados referentes a recuperação e limites de deteç̧ăo de clorpirifos e fenitrotion em casca e polpa de pepino fortificadas são apresentados nas Tabelas 1 e 2. Os cromatogramas referentes às fortificaçס̃es de 0,02 ppm de ambos os inseticidas, bem como as das testemunhas são mostrados nas Figuras 5, 6, 7, 8, 9 e 10 .

As análises das amostras fortificadas com clorpirifos apresentaram porcentagens de recuperação variaveis de 88 a $115 \%$ na casca e de 75 a $99 \%$ na polpa. 0 limite de detecção destes produtos nesses substratos ficou estabelecido em 0,02 Ppm; abaixo deste valor as impurezas interferentes, nas condiçơes em que as análises foram executadas, dificultam a quantificação dos picos nos cromatogramas. 
Tabela 1. Porcentagens de recuperaçăo de clorpirifos pelo mé todo analitico empregado em casca e polpa de pepino 'Caipira' fortificadas.

\begin{tabular}{|c|c|c|c|c|c|c|}
\hline \multirow{2}{*}{ Substrato } & \multicolumn{5}{|c|}{ Niveis de fortificaçžes (} & \multirow[b]{2}{*}{0,005} \\
\hline & 1,0 & 0,1 & 0,05 & 0,02 & 0,01 & \\
\hline \multirow[t]{2}{*}{ Casca } & 88 & 92 & 93 & 115 & $<L D$ & $<L D$ \\
\hline & 90 & 104 & 95 & 99 & & \\
\hline \multirow[t]{2}{*}{ Polpa } & 87 & 95 & 75 & 80 & $<L D$ & $<L D$ \\
\hline & 87 & 99 & 77 & 86 & & \\
\hline
\end{tabular}

LD = limite de detecção do método

Tabela 2. Porcentagem de recuperaçăo de fenitrotion pelo método analitico empregado em casca e polpa de pepino 'Caipira' fortificadas.

Niveis de fortificaçőes (ppm)

Substrato

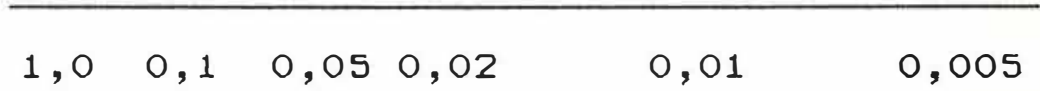

\begin{tabular}{lrrrrrll}
\hline Casca & 88 & 95 & 99 & 125 & <LD & <LD \\
& 96 & 95 & 93 & 117 & & \\
Polpa & 98 & 94 & 96 & 103 & <LD & <LD \\
& 106 & 95 & 96 & 101 & & \\
\hline
\end{tabular}

LD = limite de deteç̧ão do método 
38.

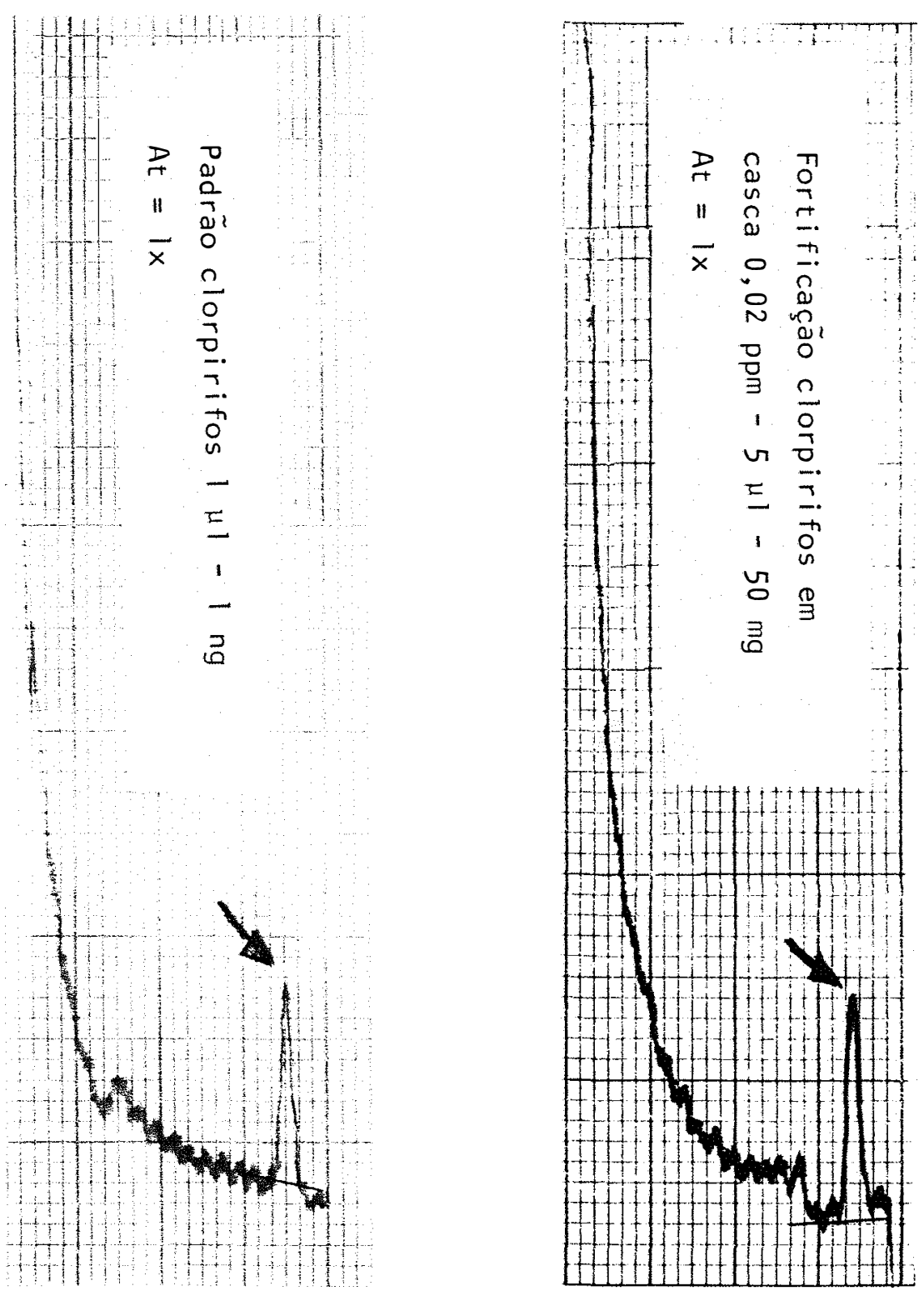

Figura 5. Cromatogramas do padrão e da amostra de casca fortificada com 0,02 ppm de clorpirifos. 
39.
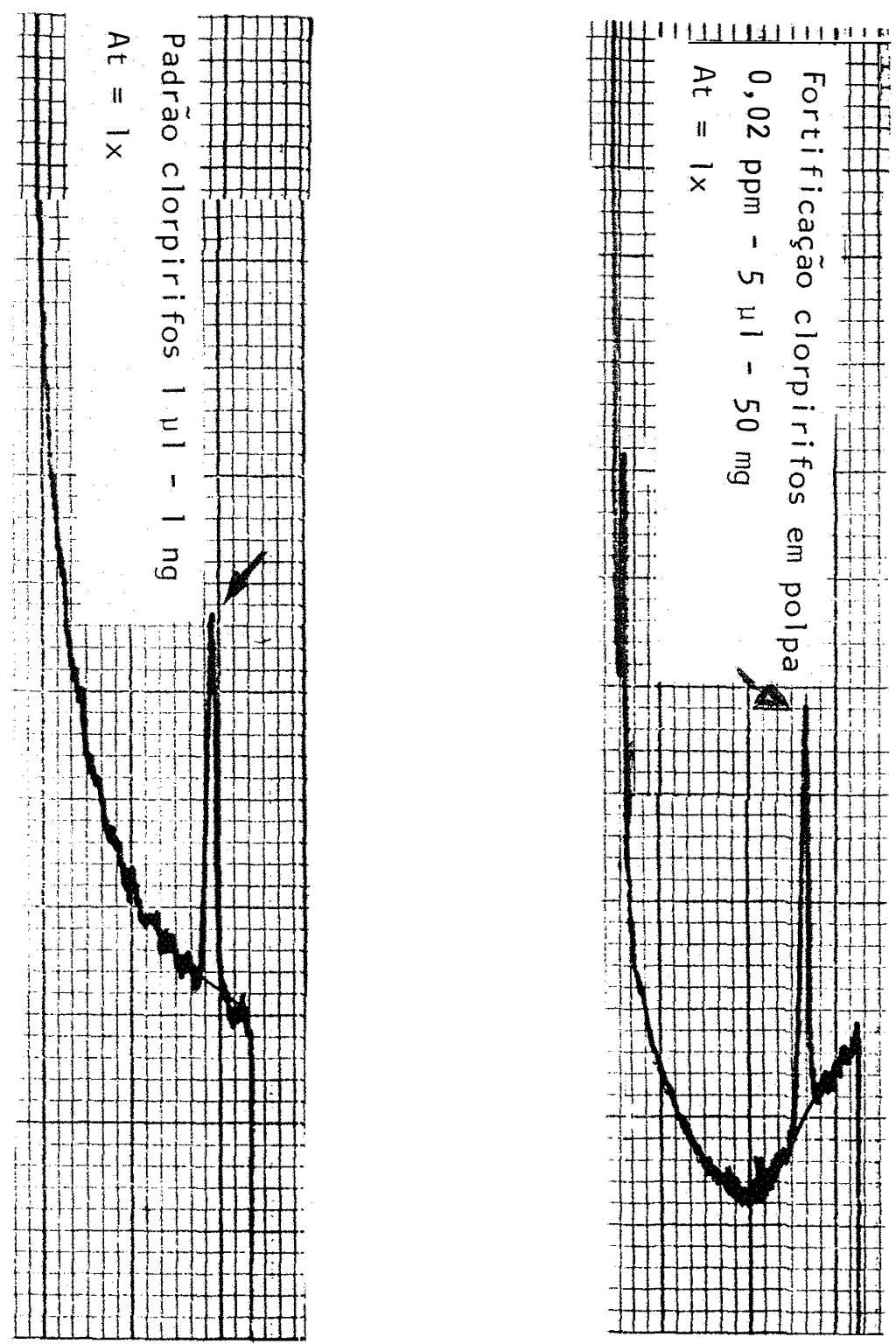

Figura 6. Cromatogramas do padrăo e da amostra de polpa fortificada com 0,02 ppm de clorpirifos 
40.
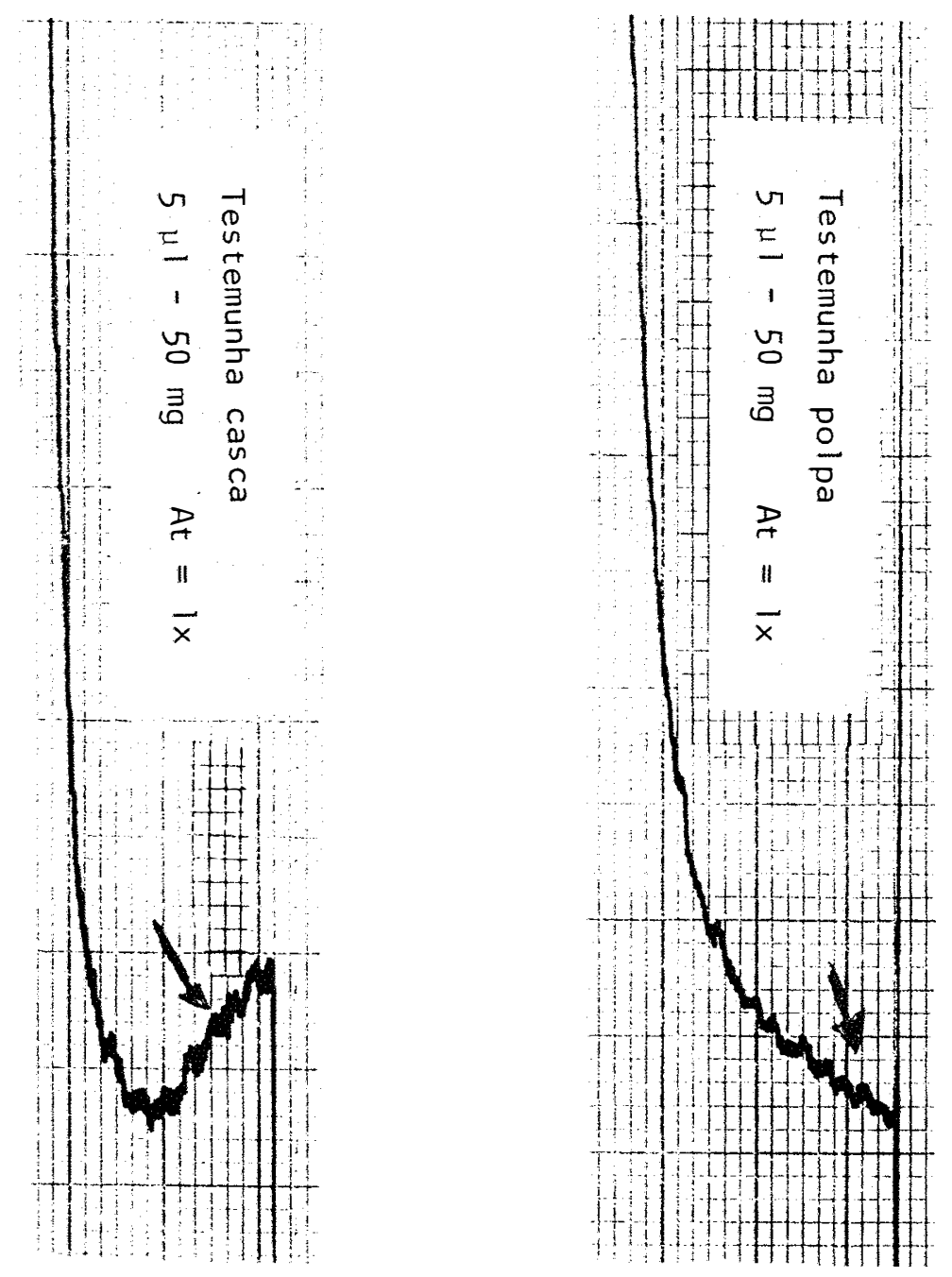

Figura 7. Cromatogramas de amostras testemunhas de casca e polpa. As setas indicam a "tempo de eluiçăo" de clorpirifos. 

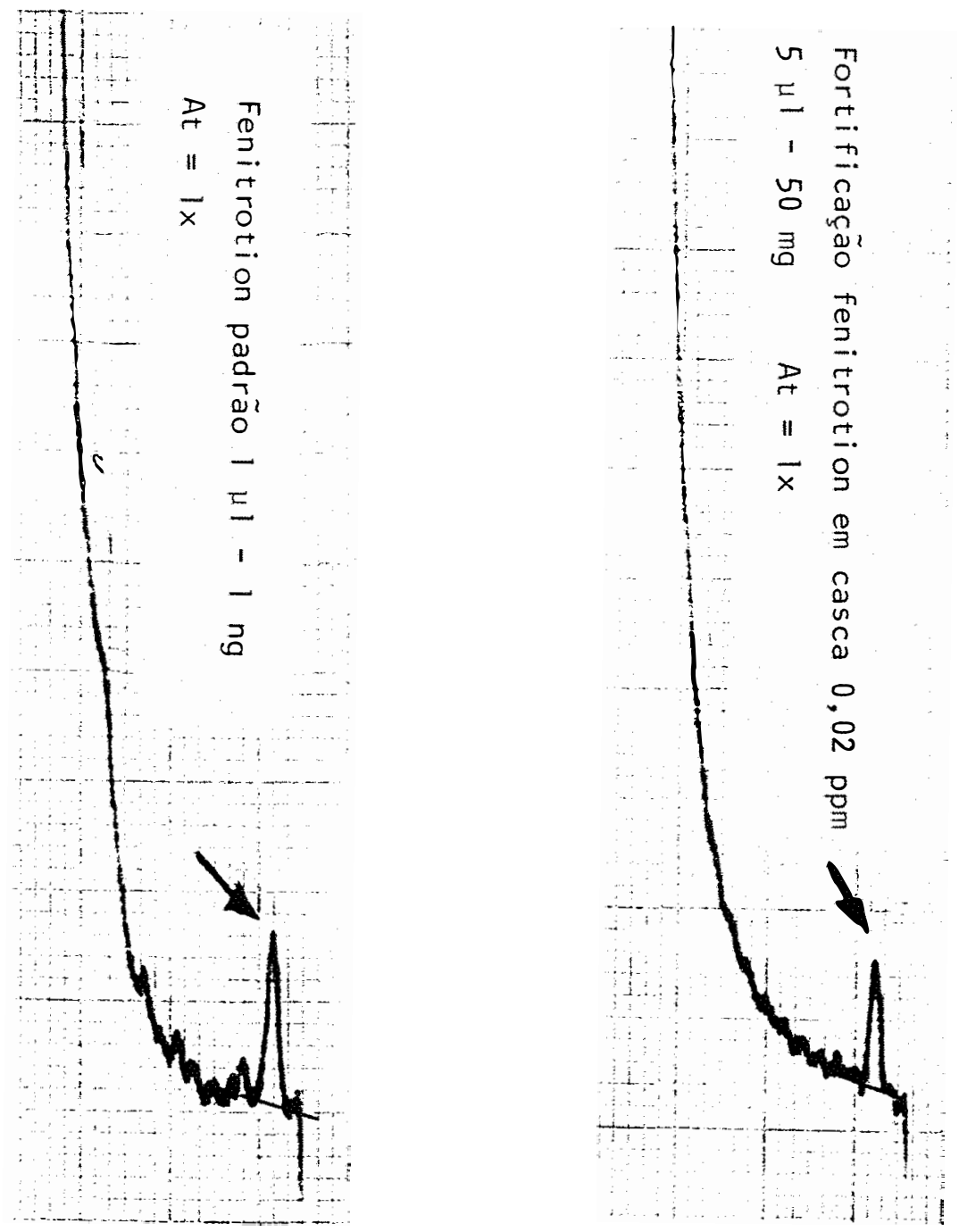

Figura 8. Cromatogramas do padrăo e da amostra de casca fortificada com 0,02 ppm de fenitrotion. 
42.
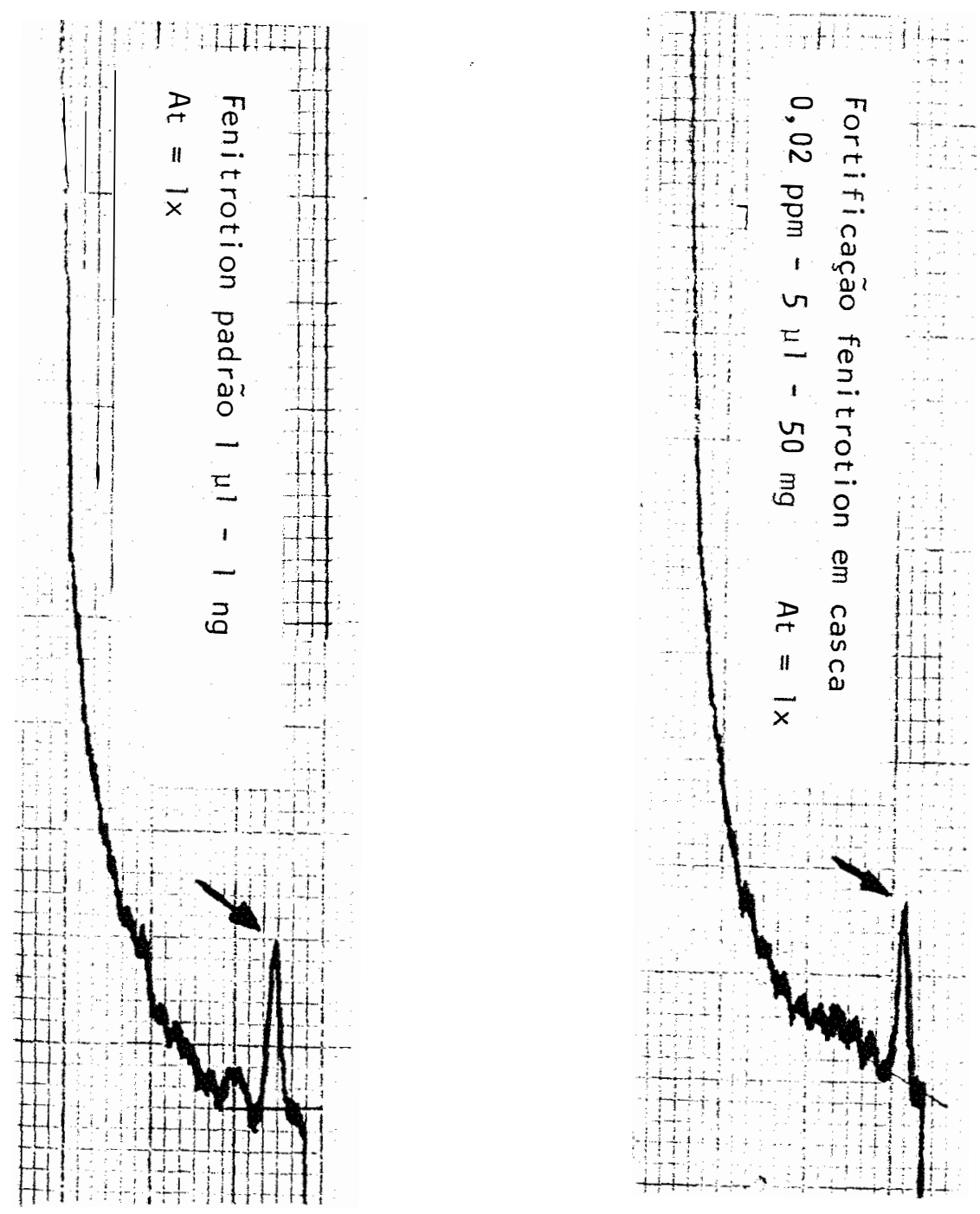

Figura 9. Cromatogramas do padrăo e da amostra de polpa fortificada com 0,02 ppm de fenitrotion. 
43.
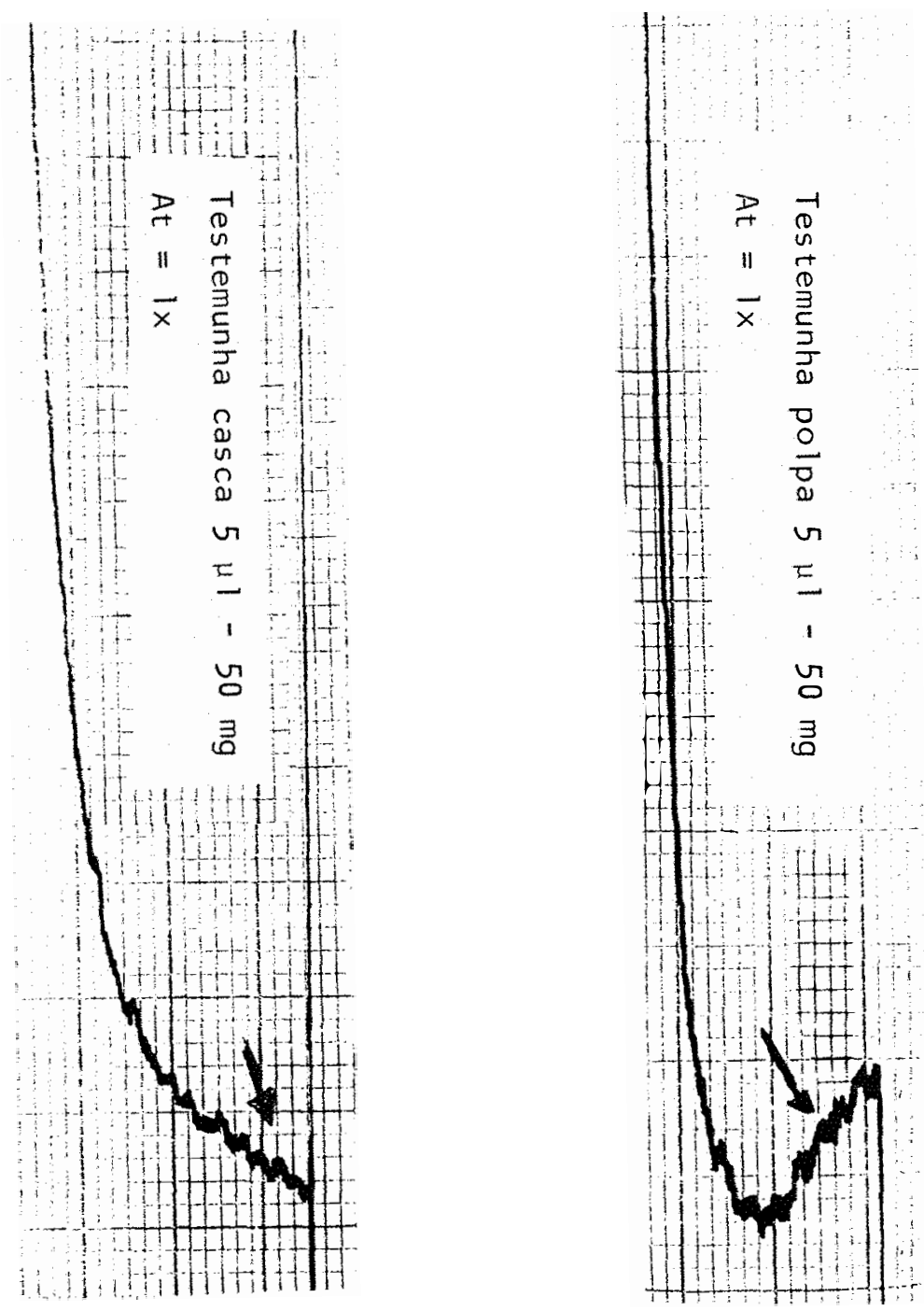

Figura 10. Cromatogramas de amostras testemunhas de casca e polpa. As setas indicam o "tempo de eluiçăo" de fenitrotion. 
44.

A recuperaçăo de fenitrotion variou de 88 a 125\% na casca e de 94 a 106\% na polpa. 0 limite de detecção deste inseticida para os dois substratos ficou estabelecido, também, em 0,02 ppm; em concentrações menores, a quantificação torna-se dificil pela ocorrencia de impurezas nos extratos.

Com os resultados obtidos nos estudos de recuperação dos inseticidas, pode-se considerar que o método analitico é altamente satisfatório para a análise desses dois inseticidas nos citados substratos.

\section{2. Residuos de clorpirifos em casca e polpa} de pepino 'Caipira'

Os resultados referentes aos residuos de clorpirifos em cascas e polpas de pepino são apresentados nas Tabelas 3 e 4 e nas Figuras 11 e 12.

Os valores dos depósitos de clorpirifos em casca, logo após a primeira aplicação foram de 0,78 e 1,68 ppm para as dosagens de 77 e 144 g i.a./halloo litros de água respectivamente; na segunda aplicação foi de 1,17 e 2,36 ppm para as mesmas dosagens, o que dá uma proporção entre os dois tratamentos, na primeira aplicação de 2,15 e na segunda de 2,02, confirmando-se a ideia de que logo após a aplicação a quantidade de residuos esperada é proporcional a quantidade de ingrediente ativo aplicado (WHO, 1974 citado por PIZANO, 1988). 
Tabeia 3. Residuos de clorpirifos en casca e polfa de pepino "Capiral provenientes de plantas tratadas com 77 g i.a./100 litros de água (tratamento A) e 144 g i.a/100 litros de água (tratamento B). La. puiverizaçăo.

\begin{tabular}{|c|c|c|c|c|c|c|}
\hline \multirow{2}{*}{$\begin{array}{l}\text { Dias apōs a } \\
\text { aplicação }\end{array}$} & \multirow{2}{*}{ Tratamento } & \multirow{2}{*}{ Substrato } & \multicolumn{3}{|c|}{ Repetições (ppm) } & \multirow{2}{*}{$\begin{array}{l}\text { Mëdia } \\
(p p m) \\
(m \pm d p)\end{array}$} \\
\hline & & & 1 & 2 & 3 & \\
\hline & \multirow{2}{*}{$A$} & Casca & 0,90 & 0,82 & 0,63 & $0,78 \pm 0,11$ \\
\hline & & Polpa & $N D^{a}$ & ND & ND & ND \\
\hline
\end{tabular}

0

\begin{tabular}{|c|c|c|c|c|c|c|}
\hline & B & $\begin{array}{l}\text { Casca } \\
\text { Polpa }\end{array}$ & $\begin{array}{c}0,78 \\
\text { ND }\end{array}$ & $\begin{array}{c}2,06 \\
N D\end{array}$ & $\begin{array}{l}2,21 \\
N D\end{array}$ & $\begin{array}{c}1,68 \pm 0,64 \\
\text { ND }\end{array}$ \\
\hline \multirow{4}{*}{3} & \multirow{2}{*}{ A } & Casca & 0,50 & 0,59 & 0,30 & $0,46 \pm 0,12$ \\
\hline & & Polpa & ND & ND & ND & ND \\
\hline & \multirow[t]{2}{*}{ B } & Casca & 0,99 & 0,82 & 1,11 & $0,97 \pm 0,12$ \\
\hline & & Polpa & ND & ND & ND & ND \\
\hline \multirow{5}{*}{8} & \multirow{2}{*}{ A } & Casca & 0,20 & 0,10 & 0,08 & $0,13 \pm 0,05$ \\
\hline & & Polpa & ND & ND & ND & ND \\
\hline & & & & & & \\
\hline & \multirow{2}{*}{ B } & Casca & 0,24 & 0,29 & 0,21 & $0,25 \pm 0,03$ \\
\hline & & Polpa & ND & ND & ND & ND \\
\hline
\end{tabular}

(a) $N D=$ Não detectāvel, ou resíduos inferiores a $0,02 \mathrm{ppm}$. 
Tabela 4. Residuos de clorpirifos en casca e polda de pepino "Calpira" firovenzentes de piantas tratadas com com 77 G i.a. 1100 i itros de aqua (tratamento A) i44 G i.a.1100 litros de agua (tratamento B). $2 a$. pulverizaçăo.

\begin{tabular}{|c|c|c|c|c|c|c|}
\hline \multirow{2}{*}{$\begin{array}{l}\text { Dias apōs a } \\
\text { apli cação }\end{array}$} & \multirow{2}{*}{ Tratamento } & \multirow{2}{*}{ Substrato } & \multicolumn{3}{|c|}{ Repetições (ppm) } & \multirow{2}{*}{$\begin{array}{c}\text { Mëdia } \\
(p p m) \\
(m \pm d p)\end{array}$} \\
\hline & & & 1 & 2 & 3 & \\
\hline & \multirow{2}{*}{$A$} & Casca & 1,38 & 1,39 & 0,74 & $1,17 \pm 0,30$ \\
\hline & & Polpa & $N D^{a}$ & ND & ND & ND \\
\hline
\end{tabular}

0

$\begin{array}{cccccc}\text { B } & \text { Casca } & 2,73 & 2,04 & 2,30 & 2,36 \pm 0,28 \\ \text { Polpa } & \text { ND } & \text { ND } & \text { ND } & \text { ND }\end{array}$

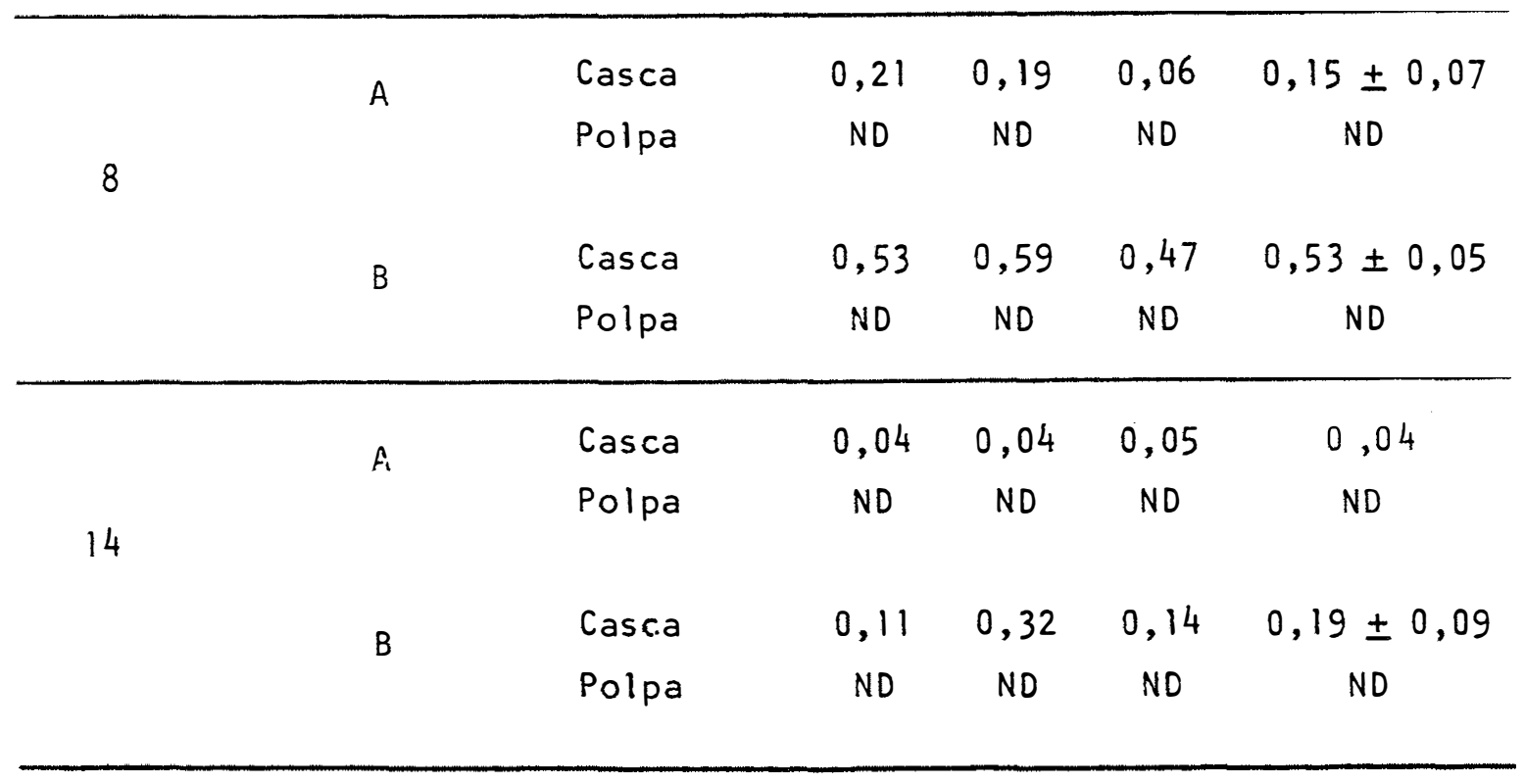

(a) $N D=$ Não detectāvel, ou resíduos inferiores a $0,02 \mathrm{ppm}$ 
47.

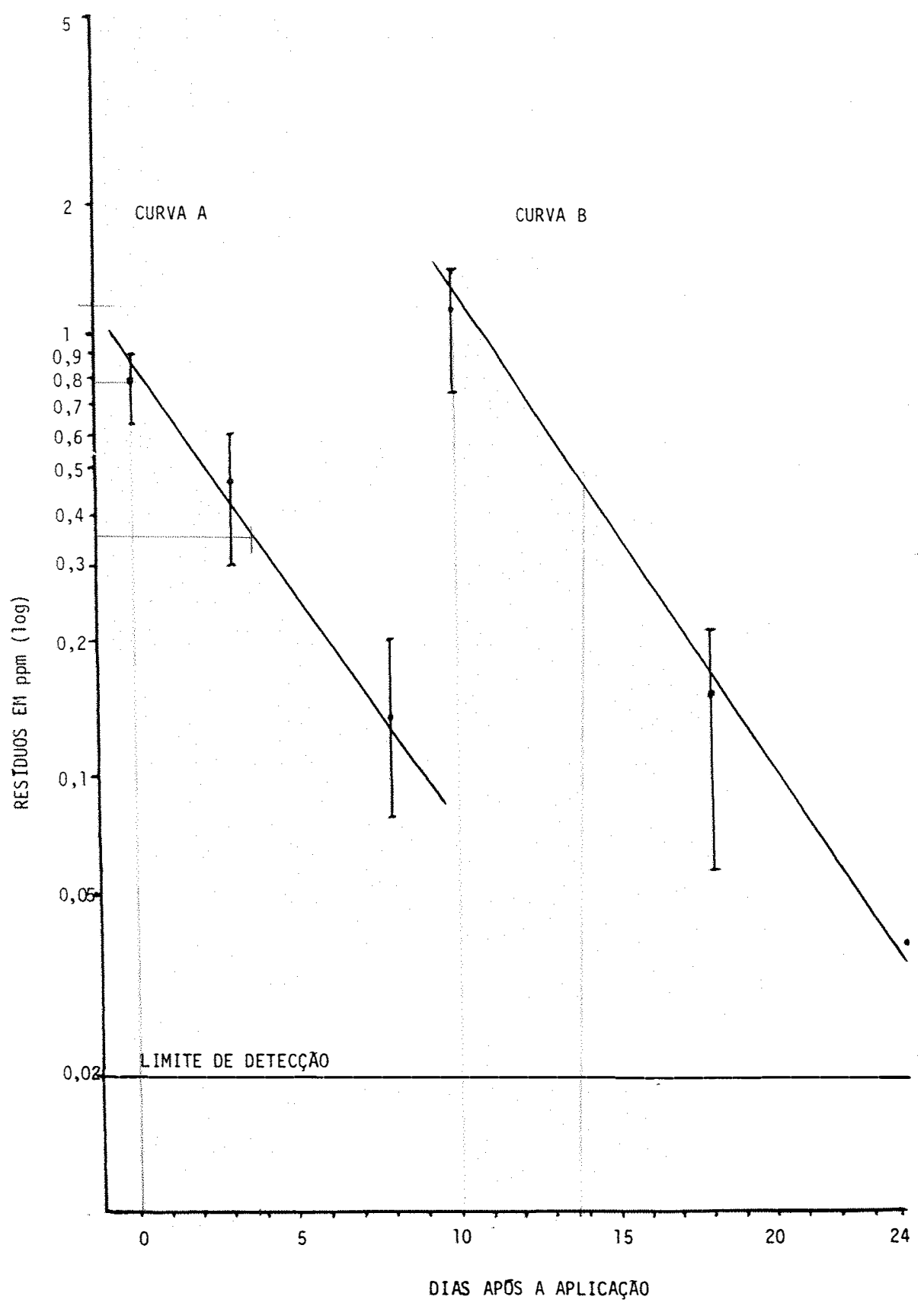

Figura 11. Curvas de degradaçăo de residuos de clorpirifos em casca de pepino 'Caipira' proveniente de plantas tratadas com 77g i.a./100 litros de agua. 1 a. pulverização (curva A), 2a. pulverização (curva B). 
48.

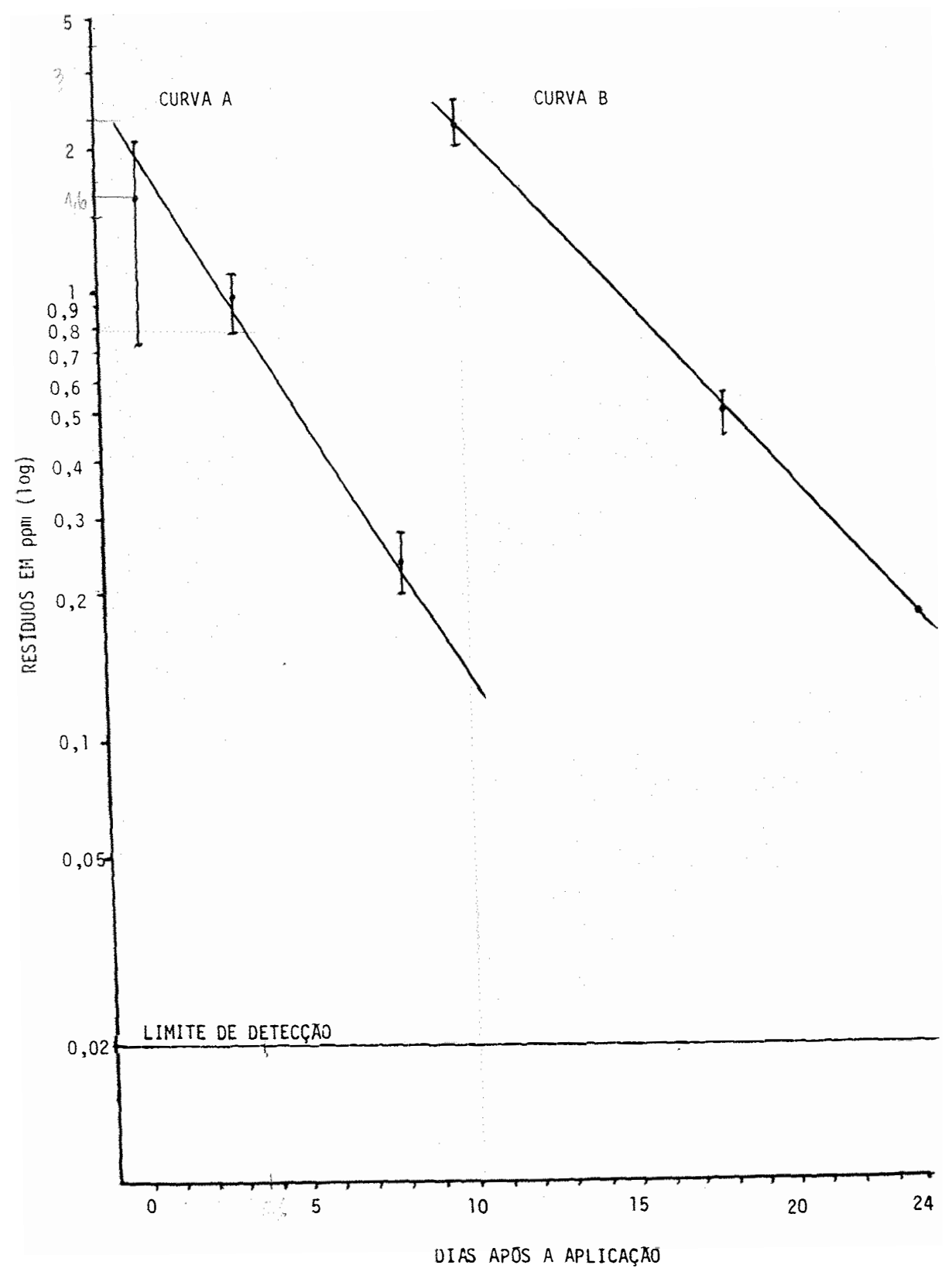

Figura 12. Curvas de degradaçăo de residuos de clorpirifos em casca de pepino 'Caipira' provenientes de plantas tratadas com 1449 i.a./100 litros de água. 1 a. pulverização (curva $A$ ). 2a. pulverizaçăo (curva B). 
Com os resultados obtidos da amostragem aos 3 dias após a primeira aplicação observa-se que houve uma redução de $42 \%$ nos niveis de residuos de clorpirifos da casca, na dose maior e $41 \%$ na dose menor; aos 8 dias, houve uma redução de 85 e $83 \%$ nos resi- duos nas dosagens maior e menor, respectivamente; com referencia à segunda aplicação, 8 dias após esta, os residuos tiveram redução da ordem de 77 e $87 \%$ nas dosagens maior e menor, respectivamente. Estes resultados são semelhantes aos de LEUCK et alii (1968) em capim bermuda e milho forrageiro, MAINI et alii (1972) em alface e aos de AL-SAMARRAIE et alii (1989) em tamaras, que também constataram uma rapida dissipação dos residuos desse inseticida.

A redução dos niveis de residuos em função do tempo decorrido após a aplicação (Figuras 11 e 12) mostra que não é possivel a distinção dos dois tipos de curvas (de degradação e de persistência), e, sim, a presença única de uma curva de degradação, devido a rápida dissipação dos residuos correspondendo a curva A da Figura 1 de GUNTHER $(1969)$.

Com os resultados mostrados nas figuras 11 e 12, os valores de meia-vida de degradação de clorpirifos foram de 3,7 e 3,6 dias para as dosagens de 77 e 144 g ial 100 litros de água, respectivamente, na primeira aplicação. Na segunda aplicação, os valores de meia-vida foram de 3,1 e 4,0 dias para as respectivas dosagens de 77 e $144 \mathrm{~g}$ i.a./100 
litros de água. Assim, pode-se observar que os valores de meia-vida foram semelhantes para as duas dosagens nas duas aplicaçŏes, podendo serem estabelecidos em 3-4 dias, o que confirma que a velocidade de desaparecimento dos residuos $e ́$ independente dos depósitos iniciais, concordando com GUNTHER \& BLINN (1955), sendo que os resultados são semelhantes aos de IWATA et alii (1985) em laranjas.

Ambos os tratamentos, na primeira aplicação, tiveram quocientes de redução dos residuos semelhantes entre as duas amostragens consecutivas, indicando que a quantidade de depósito inicial de clorpirifos em, cascas de pepino não é importante em velocidade de desaparecimento dos seus residuos, concordando com GUNTHER (1969), no que se refere ao desaparecimento dos residuos seguirem uma reação cinética de primeira ordem.

Baseando-se nas informaçöes de CoffIN (1964), SMITH (1966) e MEIKLE et alii (1983) a rápida diminuição nos niveis de residuos de clorpirifos deve-se principalmente a fatores atmosféricos, como altas temperaturas causando volatilização, bem como: fotodecomposição e ao rápido crescimento dos frutos.

Na polpa, não foram detectados residuos sequer ao nível de deteç̧ão do método (0,02 ppm) em ambas dosagens estudadas, verificando-se, dessa forma, que a casca (espessura média de 2,68 $\pm 1,90$ (Tabela 5), funciona como uma eficiente barreira contra a penetração do inseticida e 
que essa, é, assim, improvável, pelo menos ao nível do limite de deteç̧ão do método $(0,02 \mathrm{ppm})$.

Como as toleräncias para os pesticidas em pepino são estabelecidas com base no fruto todo (RESIDUOS de defensivos..., 1984), os residuos podem ser calculados a partir da porcentagem da casca nos frutos que e de $20 \%$ (Tabela 6) e, assim, compor os seus niveis a partir da participação porcentual de casca e da polpa, multiplicando- se os niveis de residuos da casca por 0,20 .

\section{3. Residuos de fenitrotion em casca e polpa de pepino "Caipira"}

Os resultados referentes aos residuos de fenitrotion săo apresentados nas Tabelas 7 e 8 e nas Figuras 13 e 14

Os valores dos depositos de fenitrotion em casca logo após a primeira pulverização foram de 2,05 e 4,70 ppm para as dosagens de 150 e 300 g i.a./100 litros de água, respectivamente, e na segunda pulverização foi de 1,78 e 4,61 ppm para as mesmas dosagens, o que dá uma proporção entre os dois tratamentos de 2,29 na primeira aplicação e na segunda de 2,59, concordando com a observação da WHO citada por PIZANO (1988), já discutida anteriormente para clorpirifos. 
Tabela 5. Avaliaçöes da espessura das cascas de pepino (mm).

Espessura das cascas (mm) (100 amostras)

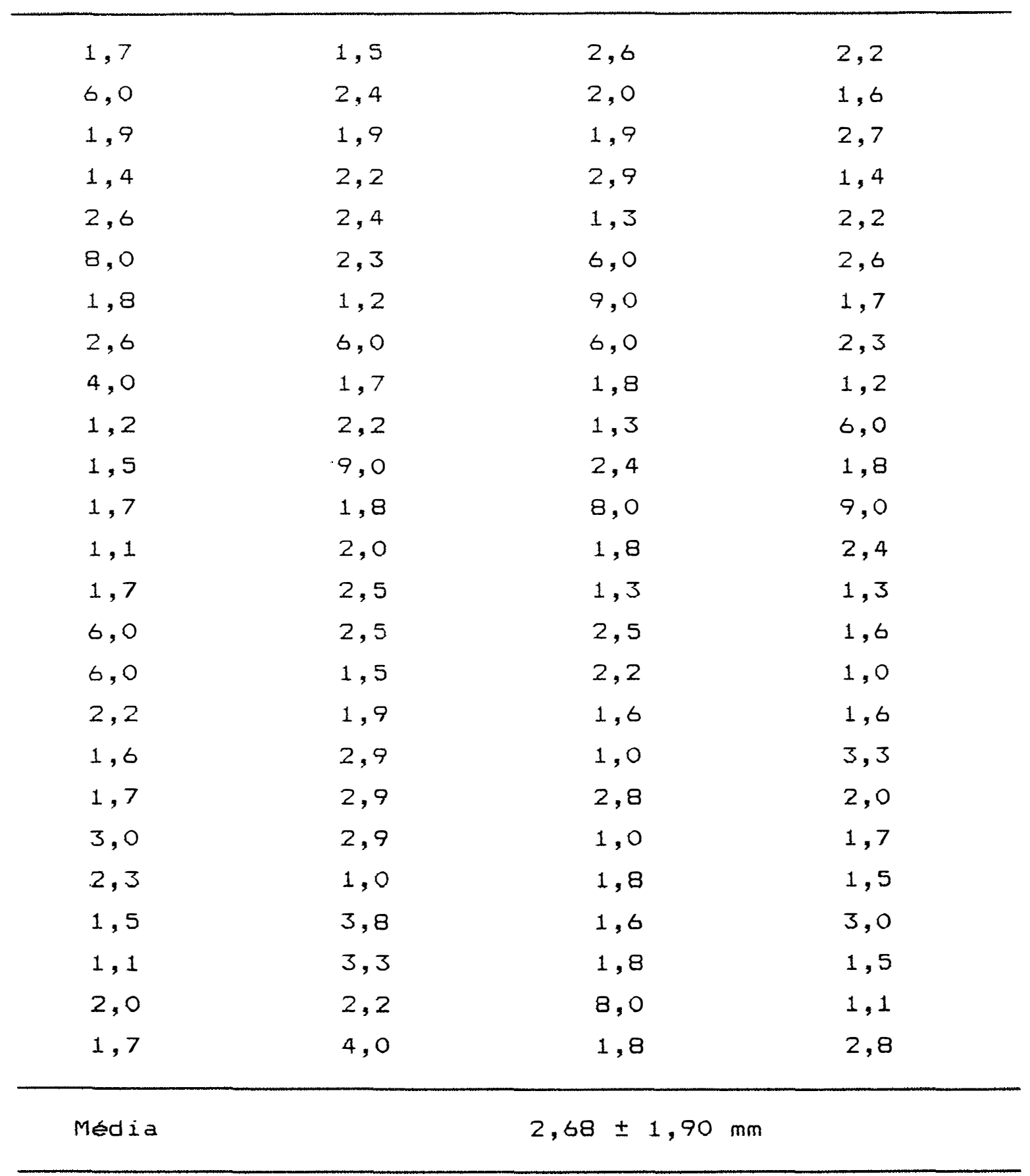


53.

Tabela 6. Peso das cascas e polpas de pepino.

\begin{tabular}{|c|c|}
\hline Casca & Polpa \\
\hline 39 & 156 \\
\hline 51 & 157 \\
\hline 45 & 320 \\
\hline 32 & 356 \\
\hline 48 & 153 \\
\hline 50 & 131 \\
\hline 51 & 174 \\
\hline 32 & 133 \\
\hline 48 & 198 \\
\hline 43 & 349 \\
\hline 47 & 136 \\
\hline 45 & 134 \\
\hline 57 & 290 \\
\hline 61 & 318 \\
\hline 61 & 138 \\
\hline 47 & 237 \\
\hline 33 & 232 \\
\hline 50 & 127 \\
\hline 64 & 151 \\
\hline 61 & 260 \\
\hline 56 & 179 \\
\hline 54 & 193 \\
\hline 57 & 214 \\
\hline 62 & 118 \\
\hline 62 & 169 \\
\hline 51 & 115 \\
\hline 54 & 181 \\
\hline 48 & 111 \\
\hline 46 & 231 \\
\hline 57 & 222 \\
\hline Media $50,40 \pm 8,680$ & $196,1 \pm 70,669$ \\
\hline
\end{tabular}


Tabela 7. Residuos de fenitrotion em casca e poipa de pepino "Caiplra" provenientes de plantas tratadas com 150 g l.a./100 litros de juua (tratamento A) e 300 马 i.a./100 litros de água (tratamento B). 1a. pulverizaçăo.

\begin{tabular}{|c|c|c|c|c|c|c|}
\hline \multirow{2}{*}{$\begin{array}{l}\text { Dias apōs a } \\
\text { aplicação }\end{array}$} & \multirow{2}{*}{ Tratamento } & \multirow{2}{*}{ Substrato } & \multicolumn{3}{|c|}{ Repetições (ppm) } & $\begin{array}{l}\text { Mëdia } \\
\text { (ppm) }\end{array}$ \\
\hline & & & 1 & 2 & 3 & $(m \pm d p)$ \\
\hline & \multirow{2}{*}{ A } & Casca & 2,44 & 1,67 & 2,04 & $2,05 \pm 0,31$ \\
\hline & & Polpa & NDa & 0,02 & ND & 0,02 \\
\hline
\end{tabular}

0

$\begin{array}{llllll}\text { B Casca } & 5,09 & 4,30 & 4,71 & 4,70 \pm 0,32 \\ & \text { Polpa } & 0,02 & 0,04 & \text { ND } & 0,03 \pm 0,01\end{array}$

\begin{tabular}{|c|c|c|c|c|c|c|}
\hline \multirow{4}{*}{3} & \multirow{2}{*}{$A$} & Casca & 0,10 & 0,12 & 0,06 & $0,09 \pm 0,02$ \\
\hline & & Polpa & ND & ND & ND & ND \\
\hline & \multirow{2}{*}{ B } & Casca & 0,53 & 0,53 & 0,42 & $0,49 \pm 0,05$ \\
\hline & & Polpa & ND & ND & ND & ND \\
\hline \multirow{4}{*}{8} & \multirow{2}{*}{ A } & Casca & ND & ND & ND & ND \\
\hline & & Polpa & ND & ND & ND & ND \\
\hline & \multirow{2}{*}{ B } & Casca & ND & ND & ND & ND \\
\hline & & Polpa & ND & ND & ND & ND \\
\hline
\end{tabular}

(a) $N D=$ Não detectāvel, ou resíduos inferiores a $0,02 \mathrm{ppm}$ 
Tabela 8. Residuos de fenitrotion em casca e polda de pepino "Caipira" provenuentes de plantas tratadas com iso g i.a.litoo litros de agua (tratamento A) e 300 g 1.a.1100 i itros de aqua (tratamento B.). 2a. pulverizaçăo.

\begin{tabular}{|c|c|c|c|c|c|c|}
\hline \multirow{2}{*}{$\begin{array}{l}\text { Dias apōs a } \\
\text { aplicação }\end{array}$} & \multirow{2}{*}{ Tratamento } & \multirow{2}{*}{ Substrato } & \multicolumn{3}{|c|}{ Repetições (ppm) } & \multirow{2}{*}{$\begin{array}{c}\text { Mëdia } \\
(p p m) \\
(m \pm d p)\end{array}$} \\
\hline & & & 1 & 2 & 3 & \\
\hline \multirow{4}{*}{0} & \multirow{2}{*}{$A$} & Casca & 1,61 & 1,68 & 2,06 & $1,78 \pm 0,20$ \\
\hline & & Polpa & NDa & ND & ND & ND \\
\hline & \multirow{2}{*}{$B$} & Casca & 5,42 & 2,70 & 5,71 & $4,61 \pm 1,35$ \\
\hline & & Polpa & ND & ND & ND & ND \\
\hline \multirow{5}{*}{8} & \multirow{2}{*}{ A } & Casca & ND & 0,04 & ND & 0,04 \\
\hline & & Polpa & ND & ND & ND & ND \\
\hline & & & & & & \\
\hline & \multirow{2}{*}{$B$} & Casca & 0,02 & 0,02 & ND & 0,02 \\
\hline & & Polpa & ND & ND & ND & ND \\
\hline \multirow{5}{*}{14} & \multirow{2}{*}{ A } & Casca & ND & ND & ND & ND \\
\hline & & Polpa & ND & ND & ND & ND \\
\hline & & & & & & \\
\hline & \multirow{2}{*}{ B } & Casca & ND & ND & ND & ND \\
\hline & & Polpa & ND & ND & ND & ND \\
\hline
\end{tabular}

(a) $N D=$ Não detectāivel, ou resíduos inferiores a $0,02 \mathrm{ppm}$. 
56.

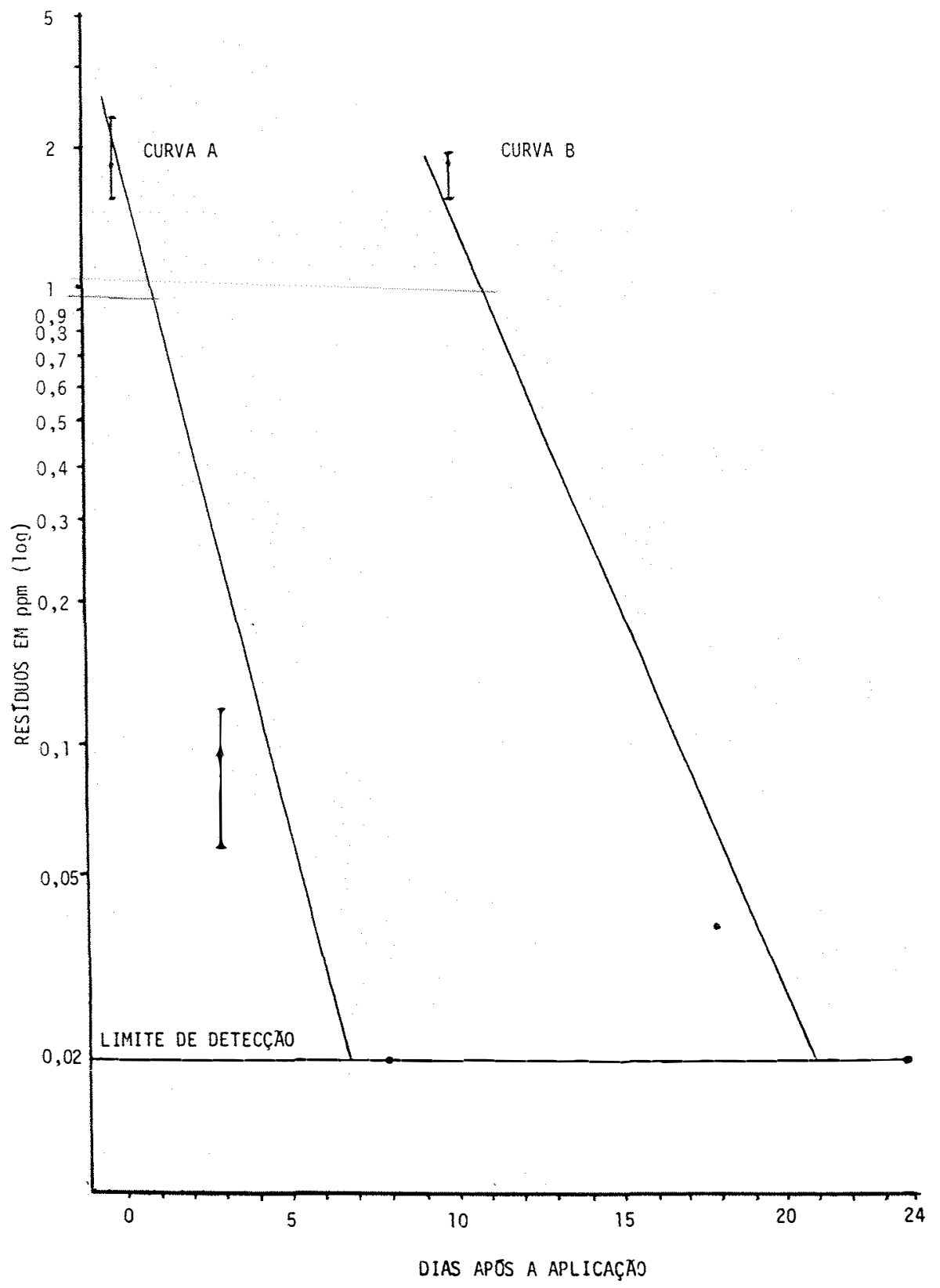

Figura 13. Curvas de degradação de fenitrotion em casca de pepino 'Caipira' provenientes de plantas tratadas com $150 \mathrm{~g}$ i.a.l100 litros de áqua. 1a. pulverizaçăo (curva A). 2a. pulverizaçăo (curva B). 


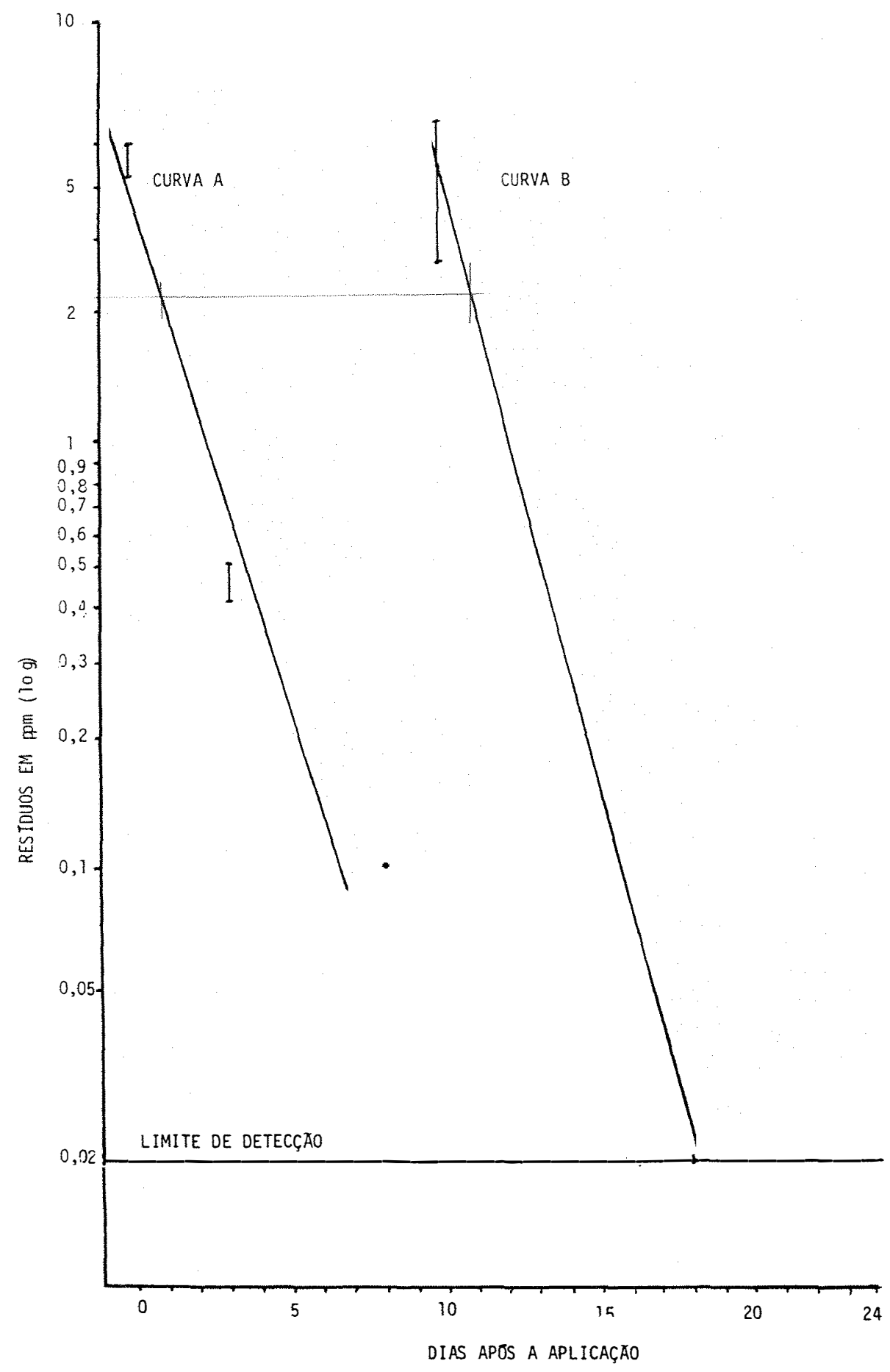

Figura 14. Curvas de degradaçăo de fenitrotion em casca de pepino 'Caipira' provenientes de plantas tratadas com 300 g i.a.l100 litros de água. 1a. pulverização (curva $A$ ). 2a. pulverizaçăo (curva B). 
58.

Os resultados apresentados nas Tabelas 7 e 8 mostram que houve uma redução dos niveis de residuos na casca em 90 e 96\% para as dosagens maior e menor, respectivamente, aos 3 dias após a primeira pulverização; aos 8 dias os residuos foram detectados em apenas 3 amostras de casca. Estes resultados são semelhantes aos de JOIA \& KALRA (1974) em quiabo, AL-SAMARRAIE et alii (1989) em tâmaras e HANDA et alii (1989) em couve-flor e repoltio, que também apresentaram uma rápida degradação do inseticida.

Da mesma maneira que ocorreu com clorpirifos, a rápida diminuição dos niveis de residuos (Figura 13 e 14 ) mostram que não é possivel a distinção dos dois tipos de curvas (de degradação e de persistência) e sim a presença única de uma curva de degradação, correspondendo a curva A da Figura 1 de GUNTHER (1969).

Com base nas figuras 13 e 14 os valores de meia-vida de degradação de fenitrotion foram de um dia para ambas as dosagens nas duas aplicaçơes, confirmando, da mesma maneira, como o clorpirifos, que a velocidade de desaparecimento dos residuos é independente dos depósitos iniciais, de acordo com GUNTHER \& BLINN (1955), e sendo semelhante aos resultados de HANDA et alii (1989) em couve-flor.

Ambos os tratamentos, nas duas pulverizaçơes, tiveram quocientes de redução semelhantes entre duas amostragens consecutivas, indicando que a quantidade de depósito inicial de fenitrotion em cascas de pepino não é importante 
na velocidade de desaparecimento de residuos, como da mesma maneira que o clorpirifos segue uma reação cinética de primeira ordem, como explicado por GUNTHER (1969).

o desaparecimento dos residuos dos dois inseticidas foram rapidos mas os de fenitrotion foram menos persistentes, o que é comentado por CAVERO (1985). Embora as pressões de vapor de ambos inseticidas sejam baixas, SMITH (1966) explica que clorpirifos desaparece rapidamente por volatilização; a radiação ultravioleta da luz solar como cita GREENHALGH \& MARSHALL (1976) e SMITH (1966), bem como o rápido crescimento dos frutos, COFFIN (1964), podem também ser responsáveis pela dissipação dos residuos.

Como pode ser observado, (Tabela 5), houve deteç̧ão de residuos de fenitrotion na polpa de algumas amostras da colheita realizada logo apos a primeira aplicação, indicando uma rápida penetração e em niveis variáveis de 0,02 a 0,04 ppm. Isso significa que houve penetração do inseticida atraves das cascas dos frutos, e que embora essa penetração seja um fato, ela o é em niveis muito baixos, muito provavelmente, com efeitos toxicologicos insignificantes.

Da mesma maneira que foi discutida para clorpirifos, os residuos de fenitrotion também podem ser calculados a partir da porcentagem da casca nos frutos que é de $20 \%$ e assim estimar os residuos para a fruta toda, multiplicando-se os valores por 0,20. Desta maneira, verifica-se 
que a dosagem de 150 g i.a./100 litros de água apresentou niveis de residuos inferiores a tolerância estabelecida pela legislação que é de 0,5 ppm (GELMINI \& NOVO, 1987), mesmo logo após a aplicação, já para a dosagem de 300 g i.a./100 litros de água, os residuos estimados para a fruta toda atinge a toleráncia estabelecida em 0,5 ppm três dias após a aplicação. Certamente a observação do período de carência de 14 dias (GELMINI \& NOVO, 1987) resultaŕa na ocorrência de niveis de residuos tóxicos perfeitamente dentro dos limites estabelecidos pela legislação, o que ressalta a importância da observação da boa prática agricola. 


\section{CONCLUSOES}

A partir dos resultados obtidos ria presente pesquisa, concluiu-se que:

a. O método analitico empregado para análise dos residuos de clorpirifos e fenitrotion em casca e polpa de pepino revela-se adequado, permitindo detecção de 0,02 ppm de residuos dos dois inseticidas, em ambos os substratos;

b. Os valores de meia-vida de clorpirifos variam de 3 - 4 dias, considerando-se as duas aplicações e ambas as dosagens; o de fenitrotion, é de um dia, também nas duas aplicações e em ambas as dosagens,indicando que os residuos de clorpirifos são um pouco mais persistentes que os de fenitrotion;

c. Os residuos dos dois inseticidas na casca, apresentam uma rápida degradação; 0 fenitrotion 8 dias 
após as aplicações e clorpirifos aos 14 dias, apresentam residuos abaixo do limite de deteç̧ão do método (0,02 ppm);

d. Os residuos de clorpirifos na polpa dos frutos, após as aplicações são inferiores aos limites de deteç̧ão do método analitico empregado, indicando que a casca funciona como uma barreira eficiente contra a penetração do inseticida;

e. Săo detectados residuos de fenitrotion na polpa logo após a primeira aplicação, indicando que o inseticida possui a capacidade de penetrar rapidamente na casca; entretanto, essa penetração se dá em niveis muito baixos e, provavelmente, de significado toxicológico insignificante, reduzindo-se para abaixo do limite de deteç̧ăo do método nos ievantamentos seguintes;

f. No fruto, os residuos de fenitrotion, aos trés dias após a aplicação, apresentam-se abaixo da tolerância de 0,5 ppm estabelecida pela legislação, para as cucurbitáceas;

9. Tendo sido a presente pesquisa feita com pepino tipo salada, fica evidenciado que o descascamento é uma forma de se eliminar a contaminação dos pesticidas estudados. 


\section{REFERENCIAS BIBLIOGRÁFICAS}

AL-SAMARRAIE, AI.I.; AL-HAFDH, E.; ABDUL-MAJED, K.; BASUMY, M.A. The chemical control of the lesser date moth, Batrachedra amydraula Meyr., and residue levels of organophosphate insecticides in dates. Pesticide Science, Oxford, 25: 227-30, 1989.

AMBRUS, A. Sampling for the determination of pesticide residues. In: JOINT FAO/WHO COURSE ON PESTICIDE RESIDUE ANALYSIS, Eger, 1983. Pesticide residue analysis; proceedings. Copenhagen, WHO; Rome, FAO, 1984. P.9-44.

BARBOSA, A. A proteçăo das hortaliças com piretróides sinteticos. Horticultura Brasileira, Brasilia, 2(1): 3-5, 1984.

BOLETIM ANUAL CEAGESP - 1989. Sao Paulo, CEAGESP, 1989. $114 \mathrm{p}$.

BRAUN, H.E.; MCEWEN, F.L.; FRANK, R. Residues of clorpiriphos and leptophos in three field-treated vegetable crops. Canadian Journal of Plant Science, Ottawa, 55: 133-7, Jan. 1975 . 
CAMPOS, T.B. \& TAKEMATSU, A.P. Ocorrencia do diptero minador em diversas culturas no Estado de São Paulo, Liriomyza huidobrensis Blanchard, 1926 (Diptera, Agromyzidae). o Biológico, São Paulo, 48(2): 39-41, 1982.

CAVERO, E.S. Inseticidas e acaricidas: toxicologia; receituário agronómico. 2. ed. Piracicaba, Livroceres, 1985. $412 \mathrm{p}$.

COBBE, R.V. Reavaliando as hortaliças. Horticultura Brasileira, Brasilia, 1(2): 10-7, nov. 1983.

COFFIN, D.E. Residues of parathion, methyl parathion, EPN, and their oxons in Canadian fruits and vegetables. Residue Reviews, Berlin, 7: 61-73, 1964.

COSTA, A.S.; CARVALHO, A.M.; SILVA, D.M. da. Dipteros minadores de folhas como importantes pragas de plantas económicas em São Paulo. Bragantia, Campinas, 20(22): $101-5,1961$.

DEMATTE, M.E.S.P. Comportamento de cultivares de pepino (Cucumis sativus L.) em duas epocas de semeadura. Piracicaba, 1978. 109p. (Mestrado - Escola Superior de Agricultura "Luiz de Queiroz"/USP).

DUPUIS, G. Pesticide residues in citrus. In: CIBA GEIGY AGROCHEMICALS. Citrus. Basle, 1975. P.81-8 (Technical Monographs, 4).

EBELING, W. Analysis of the basic processes in the deposition, degradation, persistence, and effectiveness of pesticides. Residue Reviews, Berlin, 3: 35-163, 1963. 
FILGUEIRA, F.A.R. ABC da olericultura: guia da pequena horta. São Paulo, Ceres, $1987.164 p$.

FRANÇA, H.F.; CORDEIRO, C.M.T.; GIORDANO, L.B. Controle da broca das cucurbitáceas em pepino. Horticultura Brasileira, Brasilia, 3(2): 47-53, 1985.

FundAç.TO DE CIENCIA E TECNOLOGIA. Def - Global II; residuos de defensivos agricolas em frutas, hortaliças, arroz, trigo, soja e grãos importados. Porto Alegre, 1986. 66p.

GALLO, D.; NAKANO, O.; SILVEIRA NETO, S.; CARVALHO, R.P.L.; BATISTA, G.C. de; BERTI FILHO, E.; PARRA, J.R.P.; ZUCCHI, R.A.; ALVES, S.B.; VENDRAMIM, J.D. Manual de entomologia agrícola. 2.ed. Săo Paulo, Agronômica Ceres, 1988. $639 \mathrm{p}$.

GARTRELL, M.J.; CRAUN, J.C.; PODREBARAC, D.S.; GUDERSON, E. Pesticides, selected elements and other chemicals in infant and toddler diet samples, October 1980 - March 1982. Journal of Association Official Analytical Chemistry, Arlington, 69(1): 123-61, Jan/Feb. 1986.

GELMINI, G.A. \& NOVO, J.P.S. Defensivos agricolas, informaçơes básicas e legislação. Campinas, Fundação Cargill, 1987. $577 \mathrm{p}$.

GIANNOTI, 0. O problema do controle quimico e os residuos de inseticidas. In: CONGRESSO LATINOAMERICANO DE ENTOMOLOGIA, 1., Cuzco, 1971. Anais. p.47-54.

GRAY, H.E. DURSBAN... A new organo-phosphorus insecticide. Dow to Earth, Midland, $21(3): 2,1965$. 
GREENHALGH, R. \& MARSHALL, W.D. Ultraviolet irradiation of fenitrothion and the synthesis of the photolytic oxidation products. Journal of Agricultural and Food Chemistry, Washington, 24(4): 708-13, 1976.

GROPPO, G.A. O controle do "minador das folhas" no Rio e em São Paulo. Correio Agrícola, São Paulo (1): 248-9, 1981 .

GUNTHER, F.A. \& JEPPSON, L.R. Residues of p-chlorophenylp-chlorobenzene-sulfonate (compound $k$-6451) on and in lemons and oranges. Journal of Economic Entomology, College Park, 47: 1027-32, 1954.

GUNTHER, F.A. \& BLINN, R.C. Analysis of insecticides and acaricides. New York, Interscience, 1955. 696p.

GUNTHER, F.A. Insecticides residues in California citrus fruits and products. Residue Reviews, Berlin, 28: 1$127,1969$.

HANDA, S.K.; DIKSHIT, A.K.; VERMA, S. Residues of fenitrotion on cauliflower(Brassica oleraceae convar botrytis var. botrytis) and cabbage (B. oleracea convar capitata var. capitata). Indian Journal of Agricultural Sciences, New Delhi, 59(1): 25-7, Jan. 1989.

HASSAL, K.A. The chemistry of pesticides: their metabo$1 \mathrm{ism}$, mode of action and uses in crop protection. London, Macmillan, 1982. 372p. 
IWATA, Y.; WALKER, G.P.; O'NEAL, J.R.; BARKLEY, J.H. Residues of acephate, amitraz, chlorpyrifos and formetanate hydrochloride on and in fruits after low - volume applications to orange trees. Pesticides Science, Oxford, $16(2): 172-8$, Apr. 1985.

JAPAN PESTICIDE INFORMATION. Sumithion. In:

Japanese pesticides guide. Tokyo, Japan Protection Association, 1987. P.21.

JOHNSON, M.W.; OATMAN, E.R.; WYMAN, S.A. Effects of insecticides on populations of the vegetable leafminer and assoclated parasites on fall pole tomates. Journal of Economic Entomology, College Park, 73(1): 67-72, 1980.

JOIA, B.S. \& KALRA, R.L. Note on the dissipation of ultralow-volume formulations of endossulfan, fenitrothion, fenthion and malathion on okra. Indian Journal of Agricultural Sciences, New Delhi, 44(12): 897-8, Dec. 1974.

LEUCK, D.B.; BOWMAN, M.C.; BECK, E.W. Durshan insecticide persistence in grass and corn forage. Journal of Economic Entomology, College Park, 61(3): 681-90, 1968.

LEUCK, D.B.; JOHNSON Jr., J.C.; BOWMAN, M.C.; KNOX, F.E.; BEROZA, M. Fenitrothion residues in corn silage and their effects on dairy cows. Journal of Economic Entomology, College Park, 64(6): 1934-99, Dec. 1971.

LORINI, I \& FOERSTER, L.A. Ocorrencia e efeito de inseticidas sobre a broca dos frutos (Diaphania nitidalis, Stoll) (Lepidoptera: Pyralidae) na cultura do pepino (Cucumis sativus L.). Anais da Sociedade Entomológica do Brasil, Porto Alegre, 16(1): 145-53, 1987. 
LUKE, M.A.; MASUMOTO, H.T.; CAIRNS, T.; HUNDLEY, H.K. Levels and incidence of pesticides residues in various foods and animal feeds analysed by the Luke multiresidue methodology for fiscal years 1982-1986. Journal of Association Official Analytical Chemistry, Arlington, 71 (2) : 415-33, Mar/Apr. 1988.

MAINI, P.; COLLINA, A.; PASSARINI, I. Residues of chlorpyrifos in various crops II. Residues after field treatment. Pesticide Science, Oxford, 3: 533-8, 1972.

MARICONI, F.A.M. Inseticidas e seu emprego no combate as pragas. 7.ed. Săo Paulo, Nobel, 1988. v.1, 305p.

MEIKLE, R.W.; KURIHARA, N.H.; DeVRIES, D.H. Chlorpyrifos: the photodecomposition rates in dilute aqueous solution and on a surface, and the volatilization rate from a surface. Archives of Environmental Contamination and Toxicology, New York, 12: 189-93, 1983.

MollHOFF, E. Determinación gas cromatográfica de residuos en plantas y muestras de terrenos después de la aplicación de preparados de la série E605 y Agritox@. Pflanzenschuutz - Nachrichten "Bayer", Leverkusen, 20(2): 589$606,1967$.

MORAES, G.J.; MAGALHães, A.A.; OLIVEIRA, C.A.V. Resisténcia de variedades de Vigna unguiculata no ataque de Liriomyza sativae (Diptera: Agromyzidae). Pesquisa Agropecuária Brasileira, Brasilia, 16(2): 219-21, 1981. 
OATMAN, E.R. \& MICHELBACHER, A.E. The melon leafminer Liriomyza pictella (Thomson) (Diptera: Agromyzidae): I I Ecological studies. Annals of the Entomological Society of America, College Park, 52(1): 83-9, , 1959.

PIZANO, M.A. Residuos de bromopropilato e clorobenzilato em cascas e polpas de laranjas 'Valencia' determinados por cromatografia em fase gasosa. Piracicaba, 1988. 101p. (Mestrado - Escola Superior de Agricultura "Luiz de Queiroz"/USP).

POE, S.L.; EVERETT, P.H.; SCHUSTER, D.J.; MusgraVe, C.A. Insecticidal effects on Liriomyza sativae larval and their parasites on tomato. Journal of the Georgia Entomological Society, Atlanta, 13(4): 322-7, 1978 .

RESidUOS de defensivos em alimentos / avaliação toxicológica/ estabelecimento de limites máximos permitidos de residuos (tolerâncias); aditivos alimentares. In: CURSO SOBRE TOXICOLOGIA DE DEFENSIVOS AGRICOLAS, 3 ., São Paulo, 1984. São Paulo, ANDEF, 1984. P.83-103.

RIGITANO, R.L.O. Residuos de ethion e fenitrothion em cascas e polpas de laranjas Hamlin determinados por cromatografia em fase gasosa. Piracicaba, 1979. 64p. (Mestrado - Escola Superior de Agricultura "Luiz de Queiroz" /USP).

ROUCHAUD, J. \& MEYER, J.A. New trends in the studies about the metabolism of pesticides in plants. Residue Reviews, Berlin, 82: 1-35, 1982. 
SASSAKI, H.M. \& KIMOTO, T. Teste de inseticidas em cultura de pepino (Eucumis sativus L.). Horticultura Brasileira, Brasilia, 4(1): 70, 1986.

SCARPELLINI, J.R. Seleçăo hospedeira, danos simulados e controle da mosca minadora de folhas Liriomyza huidobrensis (Blanchard, 1926) com produtos quimicos fisiologicos na cultura do pepino Cucumis sativus L. Piracicaba, 1989. 102p. (Mestrado - Escola Superior de Agricultura "Luiz de Queiroz"/USP).

SHARMA, R.K.; DURAZO, A.; MAYBERRY, K.S. Leafminer control increases summer squash yields. California Agriculture, Berkeley, 30(6): 21-2, 1980.

SMITH, G.N. Basic studies on Dursban insecticide. Dow to Earth, Middland, 3: 3-7, 1966.

SPENCER, E.Y. The significance of plant metabolities of insecticide residues. Residue Reviews, Berlin, 9: 15368,1965 .

TRYON, E.H.; POE, S.L.; CROMROY, H.L. Dispersal of vegetable leafminer onto a transplant production range. Florida Entomologist, Gainesville, 63(3): 292-6, 1980.

UNGARO, M.T.S.; GUINDANI, C.M.A.; FERREIRA, M.S.; PIGATI, P.; TAKEMATSU, A.P.; KASTRUP, L.F.C., ISHIZAKI, T. RESiduos de inseticidas clorados e fosforados em frutas e hortaliças. O Biológico, São Paulo, 46(7): 129-34, 1980 . 
UNGARO, M.T.S.; GUINDANI, C.M.A.; FERREIRA, M. da S.; BAGDONAS, M. Residuos de inseticidas clorados e fosforados em frutas e hortaliças (III). O Biológico, Săo Pau$10,53(7 / 12): 51-6, j u l . / d e z .1987$.

VILLAS BöAS, G.L. Métodos de controle de pragas em hortaliças. Horticultura Brasileira, Brasilia, 7(1): 3-6, 1989. 